ARTICLE

\title{
GCG inhibits SARS-CoV-2 replication by disrupting the liquid phase condensation of its nucleocapsid protein
}

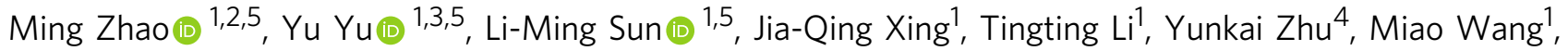
Yin $\mathrm{Yu}^{4}$, Wen Xue ${ }^{1}$, Tian Xia ${ }^{1}$, Hong Cai ${ }^{1}$, Qiu-Ying Han ${ }^{1}$, Xiaoyao Yin', Wei-Hua Li ${ }^{1}$, Ai-Ling Li', Jiuwei Cui ${ }^{3}$,

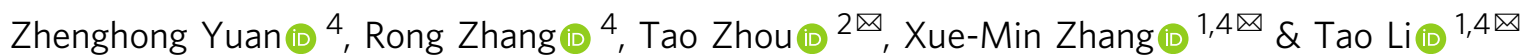

Lack of detailed knowledge of SARS-CoV-2 infection has been hampering the development of treatments for coronavirus disease 2019 (COVID-19). Here, we report that RNA triggers the liquid-liquid phase separation (LLPS) of the SARS-CoV-2 nucleocapsid protein, N. By analyzing all 29 proteins of SARS-CoV-2, we find that only $N$ is predicted as an LLPS protein. We further confirm the LLPS of N during SARS-CoV-2 infection. Among the 100,849 genome variants of SARS-CoV-2 in the GISAID database, we identify that $37 \%(36,941)$ of the genomes contain a specific trio-nucleotide polymorphism (GGG-to-AAC) in the coding sequence of N, which leads to the amino acid substitutions, R203K/G204R. Interestingly, NR203K/G204R exhibits a higher propensity to undergo LLPS and a greater effect on IFN inhibition. By screening the chemicals known to interfere with N-RNA binding in other viruses, we find that (-)-gallocatechin gallate (GCG), a polyphenol from green tea, disrupts the LLPS of $\mathrm{N}$ and inhibits SARS-CoV-2 replication. Thus, our study reveals that targeting $\mathrm{N}$ RNA condensation with GCG could be a potential treatment for COVID-19.

\footnotetext{
${ }^{1}$ State Key Laboratory of Proteomics, National Center of Biomedical Analysis, 27 Tai-Ping Road, Beijing 100850, China. ${ }^{2}$ Nanhu Laboratory, Jiaxing, Zhejiang Province 314002, China. ${ }^{3}$ Cancer Research Institute of Jilin University, The First Hospital of Jilin University, Changchun, Jilin Province 130021 , China. ${ }^{4}$ School of Basic Medical Sciences, Fudan University, Shanghai 200032, China. ${ }^{5}$ These authors contributed equally: Ming Zhao, Yu Yu, Li-Ming Sun.

凶email: tzhou@nanhulab.ac.cn; zhangxuemin@cashq.ac.cn; tli@ncba.ac.cn
} 
$\mathrm{H}$ uman coronaviruses have caused two epidemics, severe acute respiratory syndrome (SARS) and Middle East respiratory syndrome (MERS), since the 21st century. A recently identified new member of the coronavirus genera, SARSCoV-2, is responsible for the outbreak of COVID-19 pandemic, from which the world is suffering now ${ }^{1,2}$. SARS-CoV-2 shares $\sim 80 \%$ sequence similarity with SARS-CoV and entries host cells via the same receptor, angiotensin-converting enzyme 2 $(\mathrm{ACE} 2)^{3,4}$. As a highly infectious virus, SARS-CoV-2 has rapidly spread worldwide and caused a global health crisis ${ }^{5}$. As of December 1st, 2020, over 63 million people have been confirmed infected and more than 1.4 million deaths have been reported (https://covid19.who.int/). The current treatment for COVID-19 is mainly symptomatic care and supportive ${ }^{6}$. To contain the rapid global spreading of SARS-CoV-2, tremendous efforts have been made to look for efficient treatments for COVID-19. Therefore, a detailed understanding of the molecular events and the underlying mechanisms in the life cycle of SARS-CoV-2, including the viral replication and assembly, is urgently needed.

SARS-CoV-2 is an enveloped, positive-sense RNA virus containing a non-segmented single-stranded RNA genome of $\sim 30,000$ nucleotides (nt) ${ }^{1}$. The determination of the full-length genome sequence of SARS-CoV-2 allowed the analysis of the encoded proteins ${ }^{1,7-9}$. 29 proteins were predicted, including 4 structural proteins, spike (S), membrane (M), envelope (E) and nucleocapsid $(\mathrm{N})$. N protein is a highly conserved factor among coronaviruses, for example, the amino acid sequence shares $\sim 90 \%$ homology between SARS-CoV-2 and SARS-CoV ${ }^{10,11}$. Similar to $\mathrm{N}$ protein of SARS-CoV, the $\mathrm{N}^{\text {SARS-CoV-2 }}$ is a $46 \mathrm{kDa}$ protein with two domains, $\mathrm{NH}_{2}$-terminal RNA-binding domain (NTD) and $\mathrm{COOH}$-terminal dimerization domain $(\mathrm{CTD})^{11,12}$. Previous studies of coronaviruses suggested that $\mathrm{N}$ protein is an RNA-binding factor that plays a critical role in viral genome packaging and virion assembly ${ }^{13-15}$.

Many RNA-binding proteins, especially those with high percentage of intrinsically disordered region (IDR), were found to be involved in liquid-liquid phase separation (LLPS) process ${ }^{16-19}$. Protein LLPS is a physicochemical event and was recently emerged as a critical mechanism in organizing macromolecules, such as proteins and nucleic acids, into membrane-less organelles ${ }^{16,20}$. These membrane-less cellular compartments were dynamically assembled via LLPS, and conferred important capacities for the cells to initiate biological functions or reactions in response to a number of stresses ${ }^{20-25}$. Upon RNA virus infection, LLPS mediates the formation of stress granules (SGs) and P-bodies (PBs), which are critical for antiviral immunity by inhibiting viral mRNA translation and promoting RNA decay ${ }^{16-18,26,27}$. Interestingly, LLPS was also thought to be critical in viral assembly, including respiratory syncytial viral (RSV) ${ }^{28}$, measles virus $(\mathrm{MeV})^{29}$ and vesicular stomatitis virus (VSV) ${ }^{30}$. A key step during the replication of coronavirus is the association of $\mathrm{N}$ protein with viral genomic RNA and the subsequent condensation into higher-order RNA-protein complexes, which initiates the assembly of virions ${ }^{13,31}$. In the current study, by revealing the RNA-triggered LLPS of $\mathrm{N}$ protein, we have been able to find the natural chemical, GCG, can disrupt the LLPS of N protein and inhibit the replication of SARS-CoV-2. Our findings not only provide molecular details in SARS-CoV-2 infection, but also present GCG as a lead compound for the development of drug to treat COVID-19.

\section{Results}

RNA triggers the LLPS of $\mathbf{N}$ protein. As protein LLPS has been implicated to play important role in viral assembly ${ }^{29}$, we sought to study the SARS-CoV-2 proteins for their ability to undergo
LLPS. Using bioinformatic tools, IUPred2, ANCHOR2, PSPredictor, catGranule, P-Score, and PLACC ${ }^{32-36}$, we analyzed the LLPS ability of each of the 29 proteins encoded by SARS-CoV-2 genome. Only $\mathrm{N}$ protein was predicted as an LLPS protein (Fig. 1a, b, Supplementary Fig. 1, 2a and Supplementary Data 1). The known LLPS protein, RNA-binding protein fused in sarcoma (FUS $)^{19}$, and a highly structured, non-LLPS protein, mono-EGFP $(\mathrm{mEGFP})^{37}$, were respectively served as positive and negative controls for the analysis. To further understand the LLPS pattern of $\mathrm{N}$, we analyzed the amino acids and charge distribution using $R+Y$ and DDX4-like predictors ${ }^{38,39}$. We found that $\mathrm{N}$ protein exhibited the similar pattern of charged residues as DDX4-like proteins (Supplementary Fig. 2b, c).

To further study the LLPS of $\mathrm{N}$ protein, we first purified the mEGFP-tagged recombinant $\mathrm{N}$ protein and confirmed its RNAbinding capacity with electrophoretic mobility shift assay (EMSA) (Supplementary Fig. 3a, b). When $\mathrm{N}$ was incubated with different RNAs, including fragments of SARS-CoV-2 genomic RNAs [a 229-nt $3^{\prime}$ untranslated region (UTR), 229-bp double-stranded RNA (dsRNA) of the $3^{\prime}$ UTR, a 55-nt RNA segment from $5^{\prime}$ UTR or a 60-nt RNA segment from the Nsp1 coding sequence] and the synthetic analog of dsRNAs, polyinosinic-polycytidylic acid [poly (I:C)] and 5'ppp-dsRNA. We found that RNAs triggered the robust LLPS of N protein both in vitro and in vivo (Supplementary Fig. 3c, d). Using time-lapse microscopy, we observed the dynamic process of RNA-triggered LLPS of N. RNAs formed liquid condensates with $\mathrm{N}$ quickly (Fig. 1c and Supplementary Movie 1) and the smaller N-RNA droplets can fuse into bigger ones (Fig. 1d and Supplementary Movie 2), which is a hallmark of protein LLPS ${ }^{40}$. The N-RNA condensation was formed in a concentration-dependent manner (Fig. 1e-g and Supplementary Fig. $4 \mathrm{a}-\mathrm{c}$ ). We further determined the favorable $\mathrm{pH}$ (Supplementary Fig. 4d-f), salt concentrations (Supplementary Fig. 4g-i), and RNA lengths for RNA-induced LLPS of $\mathrm{N}$ protein (Supplementary Fig. 4j, k). With fluorescence recovery after photobleaching (FRAP) experiments, we showed that the photobleached fluorescence signal of N-RNA droplets can be recovered within seconds (Fig. 1h, i and Supplementary Movie 3). This result suggested that the condensates dynamically and rapidly exchange molecules with the environment, which is another feature of protein LLPS ${ }^{20}$. Collectively, these data confirmed that RNA induces the LLPS of $\mathrm{N}$ protein.

$\mathbf{N}$ undergoes LLPS in vivo. We next investigated the LLPS of $\mathrm{N}$ in vivo. We constructed a Doxycycline hyclate (Dox)-inducible $\mathrm{N}$-expressing $\mathrm{H} 1299$ cell line (Fig. 2a). Transfection of $\mathrm{N}$ expressing cells with poly(I:C) or the vRNA ( $3^{\prime}$ UTR), which is shared by all the sub-genome mRNAs ${ }^{8}$, resulted in the formation of $\mathrm{N}$ protein condensates (Fig. 2b). Using a Cyanine 5 (Cy5)labeled vRNA ( $3^{\prime}$ UTR), we confirmed that the transfected RNA formed condensations with $\mathrm{N}$ in cells (Fig. 2c and Supplementary Movie 4). Importantly, the fusion of N-RNA condensates in cells were also observed (Fig. 2d and Supplementary Movie 5). We further performed the FRAP experiment in cells and showed the active molecule-exchanging process of the N-RNA condensates in vivo (Fig. 2e, f and Supplementary Movie 6). These data indicated that the N-RNA condensates in cells were formed via LLPS.

The LLPS of different $\mathbf{N}$ variants. By performing the sequence analysis, we found that similar to SARS-CoV, the $\mathrm{N}$ protein of SARS-CoV-2 contains two domains, NTD and CTD (Supplementary Fig. 5a, b). The domain definition was also reported recently ${ }^{11}$. To understand whether these structured domains contribute to the LLPS ability, we constructed truncated $\mathrm{N}$ 
a

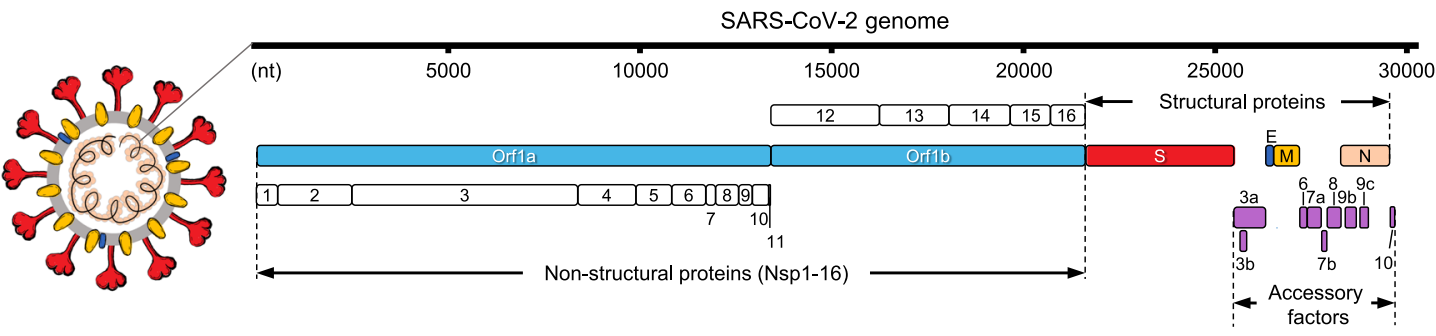

b

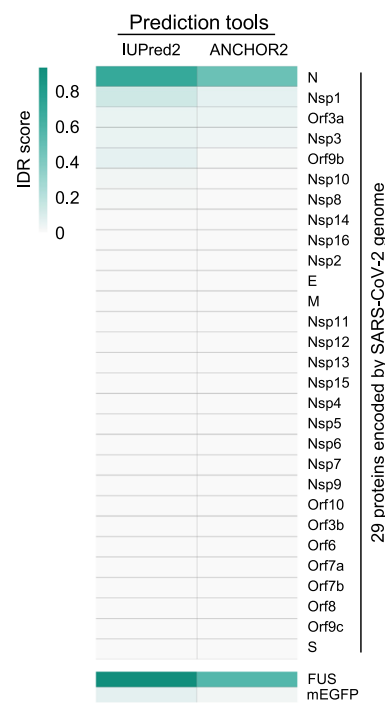

d

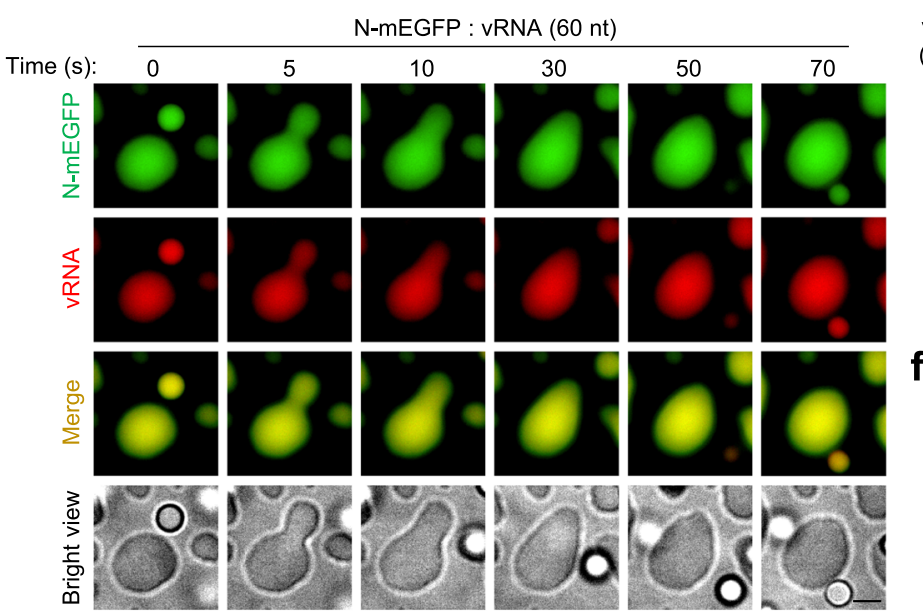

h

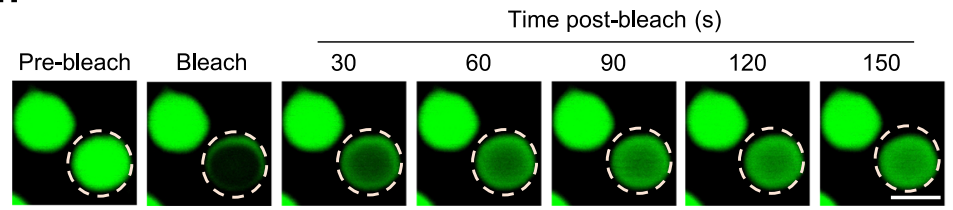

e
N-mEGFP : vRNA (60 nt)
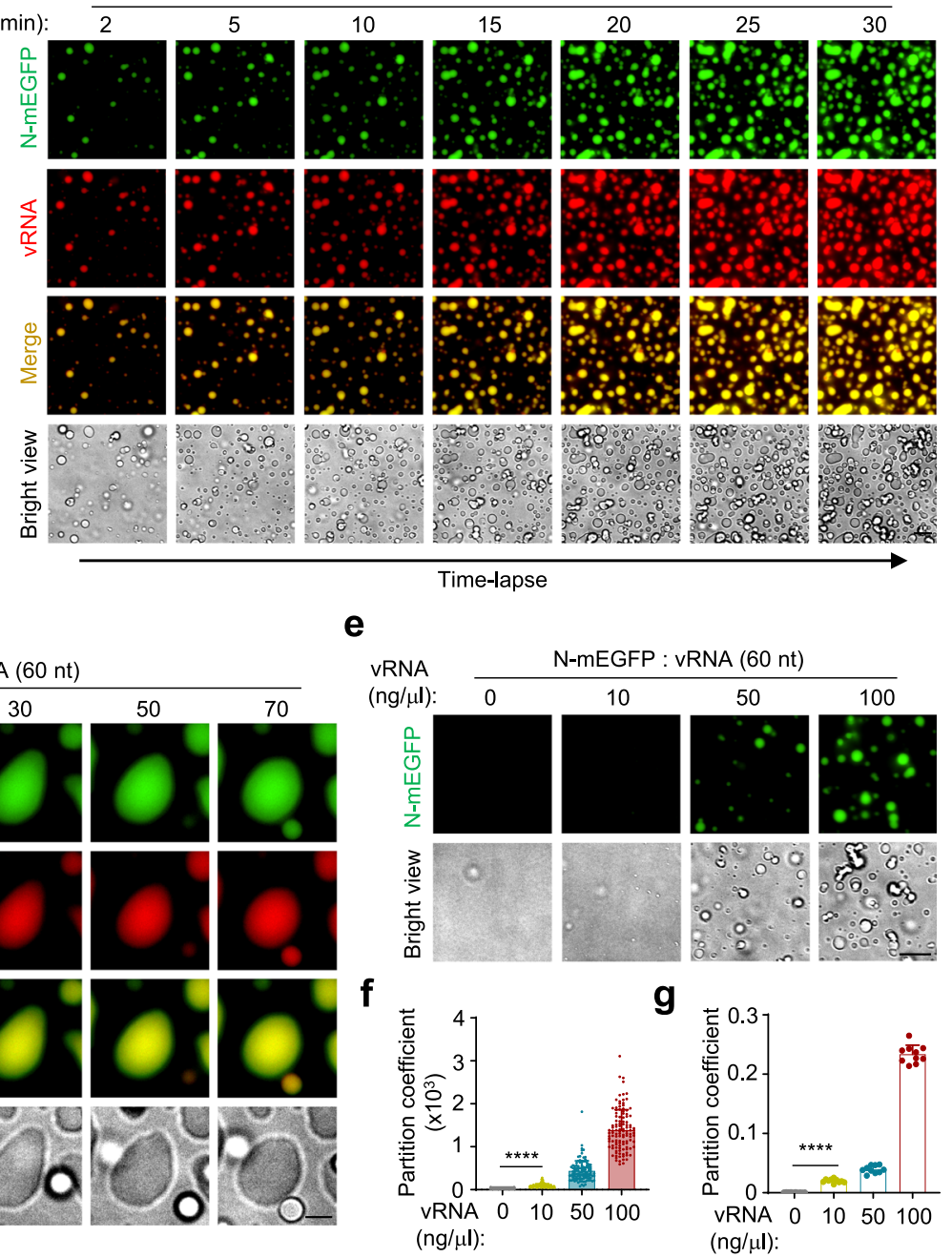

i

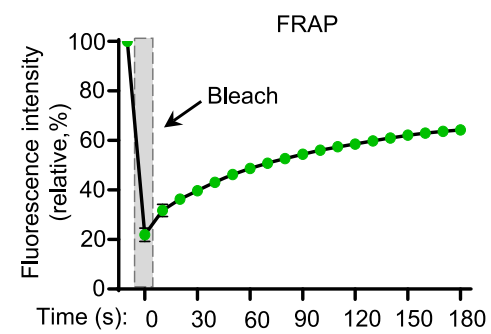

variants and purified the recombinant proteins (Fig. 3a, b). Using EMSA, we found that the deletion of any of these domains disrupted the RNA-binding ability of $\mathrm{N}$ protein (Fig. 3c). By incubating these variants with the 60 -nt viral genomic RNA, we found that none of the truncated $\mathrm{N}$ variants can undergo LLPS
(Fig. 3d-h and Supplementary Movie 7-11). To further determine the contribution of IDRs in $\mathrm{N}$ for LLPS, another variant of only CTD and NTD (connected by a 'SGGS' linker) was constructed and prepared (Supplementary Fig. $5 c$, d). We found that this variant lost the LLPS ability (Supplementary Fig. 5e, f). These 
Fig. 1 RNA triggers the LLPS of N protein. a Schematic drawing of SARS-CoV-2. $\mathbf{b}$ IDR scores of 29 proteins encoded by SARS-CoV-2 genome. FUS and mEGFP are positive and negative controls, respectively. IUPred2 and ANCHOR2 were used as prediction tools. c Time-lapse imaging of N-mEGFP protein $(20 \mu \mathrm{M})$ in the presence of Cy5-labeled 60-nt vRNA (100 ng/ $\mu \mathrm{l})$, scale bar, $10 \mu \mathrm{m}$. d Representative fluorescent images of N-mEGFP-vRNA (60 nt) condensates fusion from a time-lapse movie, scale bar, $3 \mu \mathrm{m}$. e-g LLPS of N-mEGFP protein $(20 \mu \mathrm{M})$ in the presence of indicated concentrations of $60-$ nt vRNA, scale bar, $10 \mu \mathrm{m}(\mathbf{e})$. The partition coefficient of fluorescence intensity per droplet (f) and the partition coefficient of total fluorescence intensity in each view (g) were calculated. From left to right, $n=209,1170,1026,1170$ droplets (f) from 10 randomly selected views (g). h, i FRAP analysis of vRNAinduced liquid droplets of N-mEGFP protein, scale bar, $2 \mu \mathrm{m}(\mathbf{h})$, and quantification of fluorescence intensity recovery of a photobleached N-mEGFP protein, $n=3$ biologically independent experiments (i). The white dotted circle in $\mathbf{h}$ indicated the region of photobleaching. $20 \mu \mathrm{M} \mathrm{N}$-mEGFP protein and $100 \mathrm{ng} / \mu \mathrm{l}$ 60-nt vRNA were used. Error bars, mean with s.d. (f, $\mathbf{g}, \mathbf{i})$. Two-tailed unpaired Student's $t$-test $(\mathbf{f}, \mathbf{g}),{ }^{\star \star \star \star} P<0.0001$. Data are representative of at least three independent experiments. Source data are provided as a Source Data file.

a

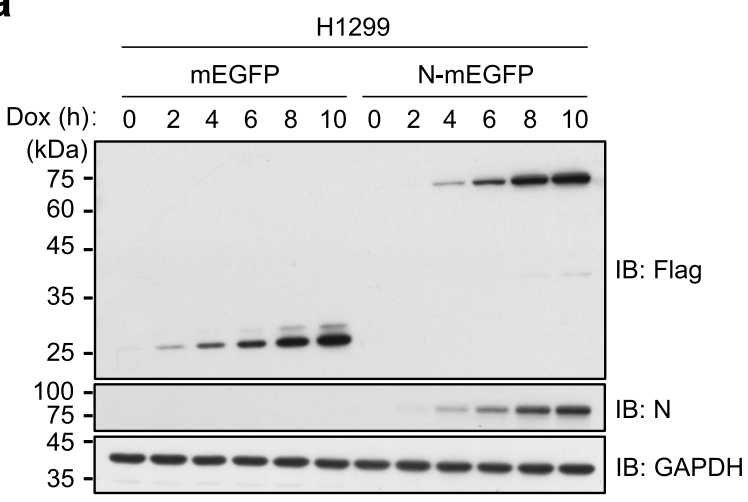

C

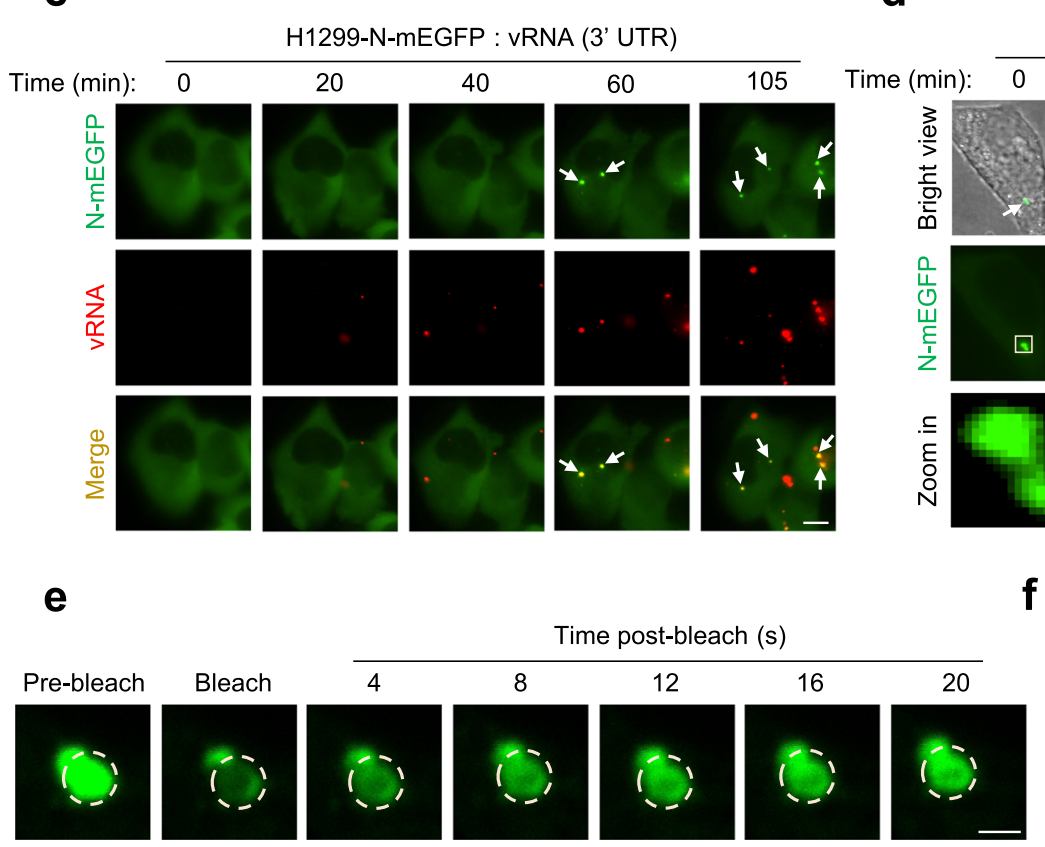

b

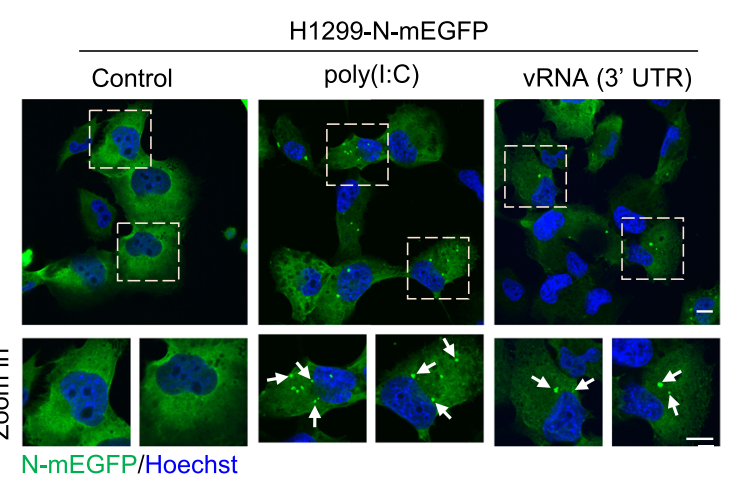

H1299-N-mEGFP : vRNA (3' UTR)

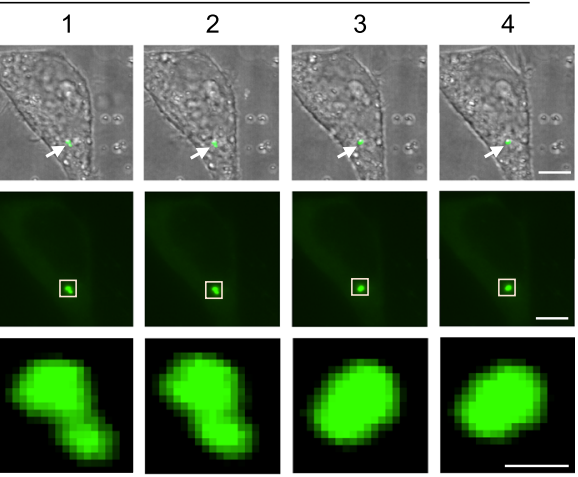

f

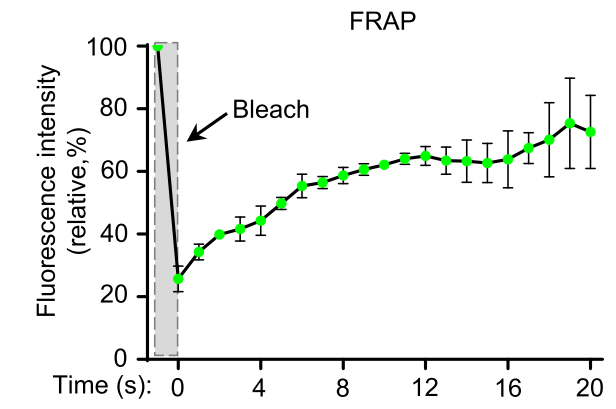

Fig. 2 N undergoes liquid-liquid phase separation in vivo. a Immunoblot analysis of the Dox-induced expression of Flag-tagged mEGFP and N-mEGFP protein in $\mathrm{H} 1299$ cells. b Representative fluorescent images of $\mathrm{H} 1299$ cells stimulated with $1 \mu \mathrm{g} / \mathrm{ml}$ poly (I:C) or vRNA ( $3^{\prime}$ UTR). Hoechst (blue), nuclear staining. Scale bar, $10 \mu \mathrm{m}$. c Time-lapse imaging of N-mEGFP protein foci in H1299 cells stimulated with $1 \mu \mathrm{g} / \mathrm{ml}$ Cy5-labeled vRNA (3' UTR). Scale bar, $10 \mu \mathrm{m}$. d Liquid droplets fusion of N-mEGFP protein in $\mathrm{H} 1299$ cells stimulated with $1 \mu \mathrm{g} / \mathrm{ml}$ poly $(\mathrm{l}: \mathrm{C})$. The white square indicated the region of fusion. Scale bars, $5 \mu \mathrm{m}$ (top, middle), $0.5 \mu \mathrm{m}$ (bottom). e FRAP analysis of liquid droplets of N-mEGFP protein in $\mathrm{H} 1299$ cells stimulated with $1 \mu \mathrm{g} / \mathrm{ml}$ poly(I:C). The white dotted circle indicated the region of photobleaching. Scale bar, $1 \mu \mathrm{m}$. $\mathbf{f}$ The quantification of fluorescence intensity recovery of a photobleached $\mathrm{N}$-mEGFP protein in H1299 cells, $n=3$ biologically independent experiments. Dox ( $100 \mathrm{ng} / \mathrm{ml}$ ) was used in H1299 cells in this work unless otherwise indicated. Error bars, mean with s.d. Data are representative of at least three independent experiments. Source data are provided as a Source Data file. 
a

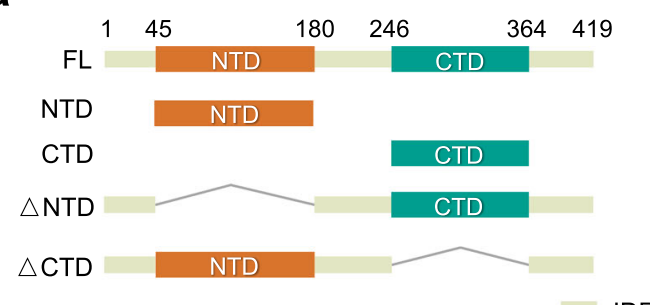

b

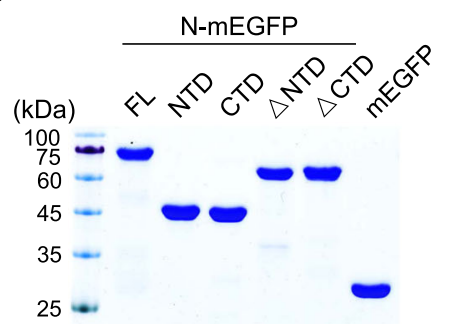

C

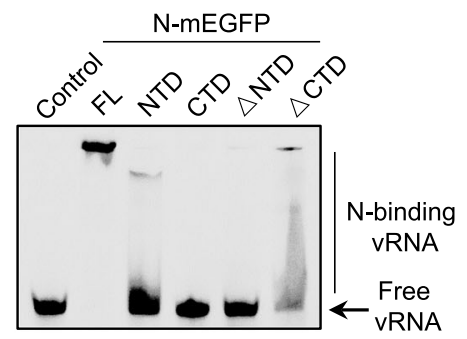

d

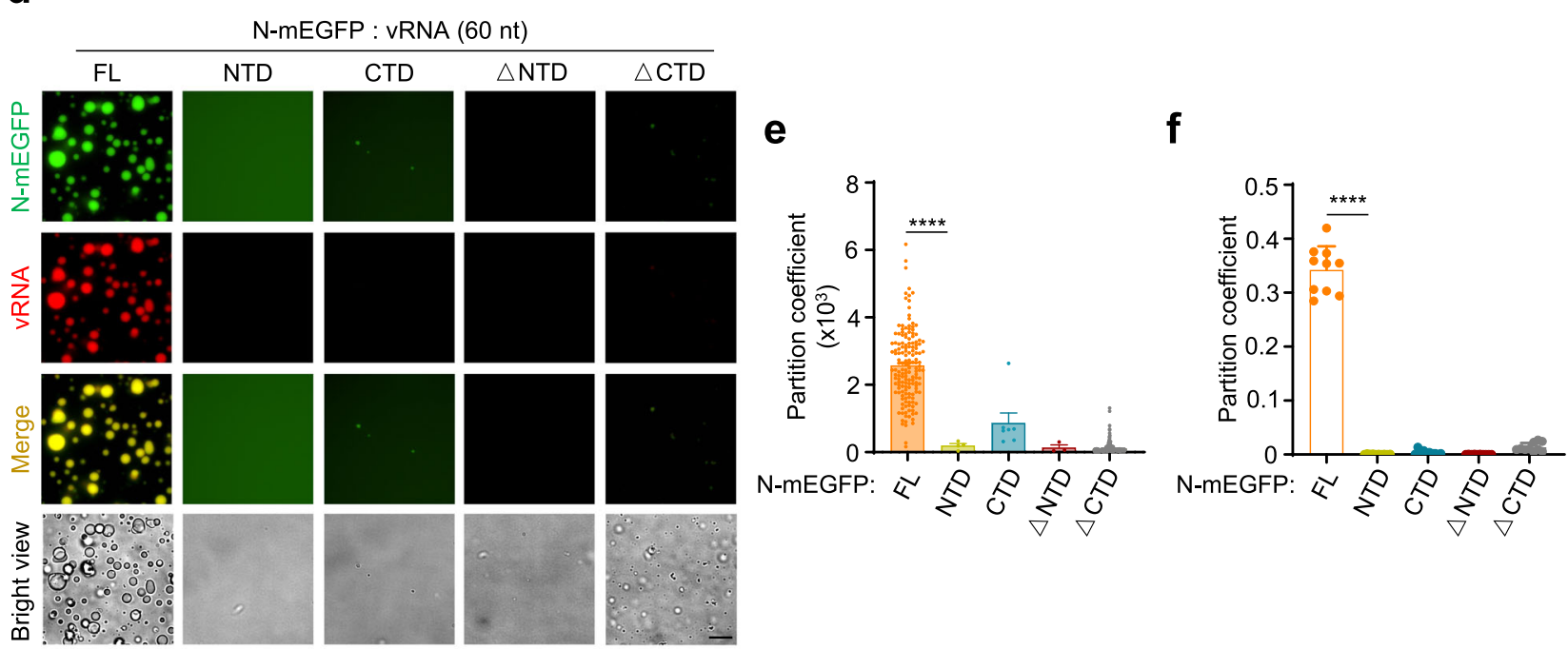

\section{g}

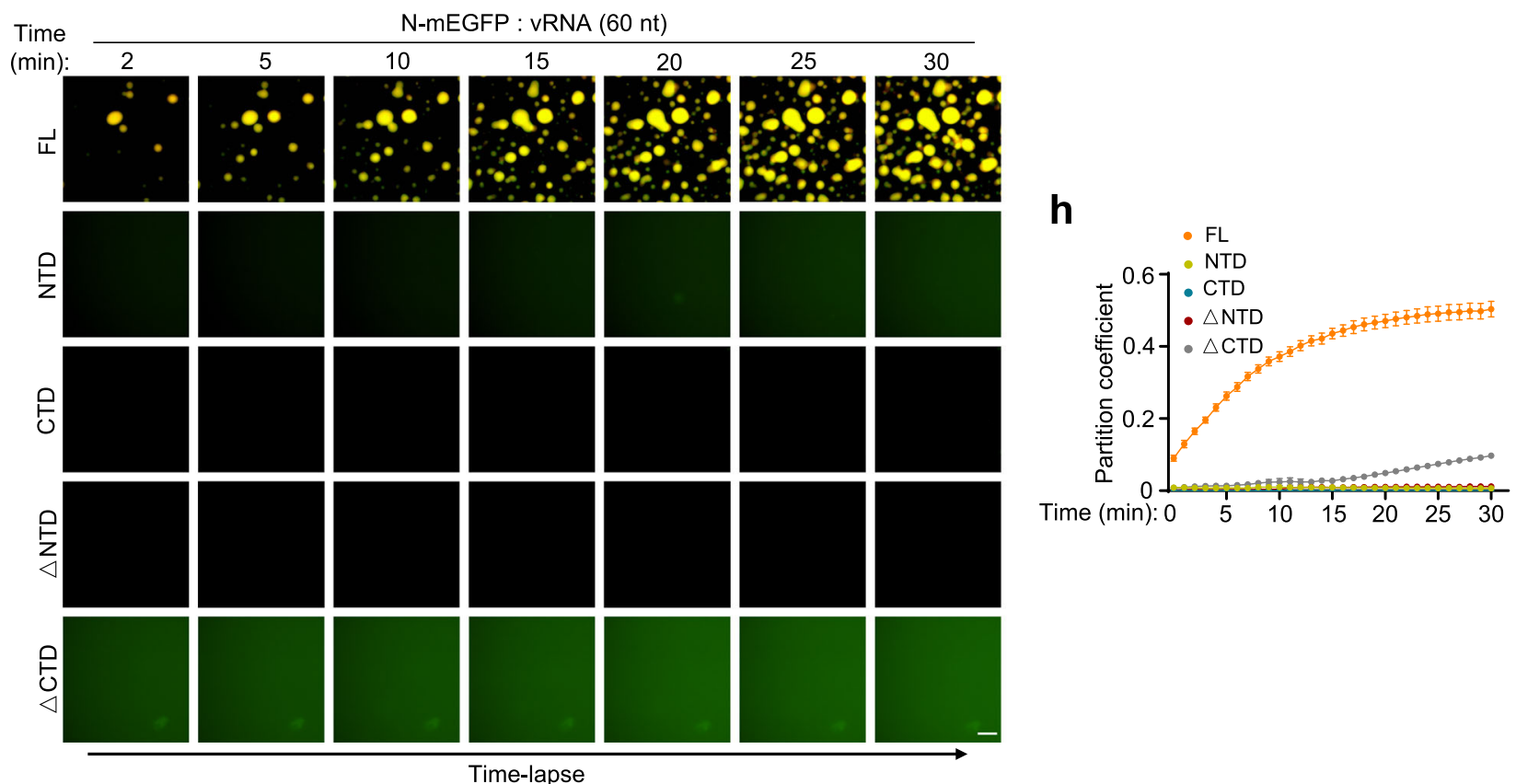

Fig. 3 The LLPS of different $\mathbf{N}$ variants. a Schematic drawing of domains of $N$ protein. $\mathbf{b}$ Coomassie brilliant blue-stained SDS-PAGE gel of purified mEGFP protein, and full length and truncations of N-mEGFP protein. $\mathbf{c}$ The RNA-binding capacity of full length and different truncations of N-mEGFP protein (1 $\mu$ M) was analyzed by EMSA. 55-nt Cy3-labeled vRNA (200 nM) was used as RNA probe. Control, mEGFP protein. d-f LLPS of full length and different truncations of N-mEGFP protein $(20 \mu \mathrm{M})$ in the presence of Cy5-labeled 60 -nt vRNA $(100 \mathrm{ng} / \mu \mathrm{l})$. The partition coefficient of fluorescence intensity per droplet (e) and the partition coefficient of total fluorescence intensity in each view (f) were calculated. From left to right, $n=1418,23,47,11,852$ droplets (e) from 10 randomly selected views $(\mathbf{f}) . \mathbf{g}$, $\mathbf{h}$ Time-lapse imaging of full length and different truncations of $\mathrm{N}$-mEGFP protein $(20 \mu \mathrm{M})$ in the presence of Cy5-labeled 60-nt vRNA $(100 \mathrm{ng} / \mu \mathrm{l})(\mathbf{g})$, and the partition coefficient $(n=8$ randomly selected views) of total fluorescence intensity (h). Scale bars, $10 \mu \mathrm{m}$ $(\mathbf{d}, \mathbf{g})$. Error bars, mean with s.d. (e, f) and mean with s.e.m. (h). Two-tailed unpaired Student's $t$-test $(\mathbf{e}, \mathbf{f}){ }^{\star \star \star \star} P<0.0001$. Data are representative of at least three independent experiments. Source data are provided as a Source Data file. 
data showed that NTD, CTD, and IDRs are all important for the $\mathrm{N}$-RNA binding and the LLPS of N.

$\mathrm{N}^{\mathrm{R} 203 \mathrm{~K} / \mathrm{G} 204 \mathrm{R}}$ gained greater ability to undergo RNA-induced LLPS. Since the first identification of the genome sequence of SARS-CoV-2 $2^{1}$, full genomic sequences of this virus from all over the world were continuously submitted to public databases, such as GISAID (https://www.gisaid.org). We analyzed 100,849 genome sequences of SARS-CoV-2 from GISAID with the attempt to examine the variability of $\mathrm{N}$-coding sequences. Surprisingly, while many nucleotide polymorphisms were found across the full length of the $\mathrm{N}$-coding sequence, a high-frequency trio-nucleotide polymorphism (GGG-to-AAC) was identified in 37\% $(36,941)$ of the genomes (Fig. 4a, Supplementary Fig. 5g and Supplementary Data 2). This GGG-to-AAC variation resulted in the amino acid substitutions, R203K/G204R, in N protein. To examine the effect of this high-frequency variation on the LLPS of $\mathrm{N}$, we prepared the recombinant proteins of these variants, $\mathrm{N}^{\mathrm{R} 203 / \mathrm{G} 204}, \mathrm{~N}^{\mathrm{R} 203 \mathrm{~K}}$, $\mathrm{N}^{\mathrm{G} 204 \mathrm{R}}$, and $\mathrm{N}^{\mathrm{R} 203 \mathrm{~K} / \mathrm{G} 204 \mathrm{R}}$ (Fig. 4b). When incubated with viral

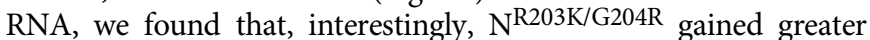
ability to undergo LLPS (Fig. 4c-g and Supplementary Movie 12, 13). We also analyzed the correlation between the mortality and R203K/G204R polymorphism of N. Our results showed that this polymorphism has little effect on the death ratio reported (Supplementary Fig. 5h). In the future, analysis of patient clinical outcomes and the coupled SARS-CoV-2 genome sequences will provide important evidences regarding the effect of $\mathrm{N}^{\mathrm{R} 203 \mathrm{~K} / \mathrm{G} 204 \mathrm{R}}$ polymorphism on the biology of SARS-CoV-2.

N inhibits RNA-induced IFN expression. According to a previous study of SARS-CoV, $\mathrm{N}$ protein inhibits the virus infectioninduced production of interferon (IFN) by interfering with the detection of viral RNA by cellular RNA sensors ${ }^{41}$. To determine the role of SARS-CoV-2 $\mathrm{N}$ protein in the RNA-induced expression of IFN, we transfected vRNA ( $3^{\prime} \mathrm{UTR}$ ) or poly(I:C) into the $\mathrm{N}$-expressing and control cells. Our data showed that the expression of $\mathrm{N}$ attenuated the intracellular RNA-triggered expression of IFN (Fig. 5a, b). We next examined the inhibitory effect of $\mathrm{N}$ proteins (both $\mathrm{N}^{\mathrm{R} 203 \mathrm{~K} / \mathrm{G} 204 \mathrm{R}}$ and $\mathrm{N}^{\mathrm{R} 203 / \mathrm{G} 204}$ ) on the RNA-induced expression of IFN. We found that the polymorphism of $\mathrm{N}^{\mathrm{R} 203 \mathrm{~K} / \mathrm{G} 204 \mathrm{R}}$, which exhibited a higher propensity to undergo LLPS in the presence of RNAs, showed a greater effect on the inhibition of IFN expression (Fig. $5 \mathrm{c}-\mathrm{i}$ ). These data indicated that the RNA-triggered phase separation procedure of $\mathrm{N}$ protein may shield viral RNAs from host RNA sensors to avoid immune surveillance. Thus, in addition to mediating the package of viral genomic RNA, $\mathrm{N}$ may also affect the host antiviral responses. Our data suggested that the inhibitory effect of $\mathrm{N}$ is linked with its ability of LLPS.

GCG inhibits LLPS of N. Given that the N-mediated genome organization process is a key step for viral assembly ${ }^{13,14}$, our findings, therefore, provided a potential target for the development of means to combat SARS-CoV-2. With this in mind, we listed several chemicals/drugs that were previously reported to interfere with the N-RNA binding or the self-aggregation of $\mathrm{N}$ protein of viruses ${ }^{42-46}$. We also included the chemicals/drugs suggested by a recent report of the proteomics study on SARS$\mathrm{CoV}-2^{9}$ (Supplementary Fig. 6). Next, we transfected poly(I:C) into the $\mathrm{N}$-expressing cells following the pre-treatment of the above chemicals/drugs. GCG blocked the RNA-triggered LLPS of $\mathrm{N}$, while other drugs did not show detectable effect (Fig. 6a). Data from multiple views were calculated and analyzed statistically (Fig. 6b). Using a Cy5-labeled vRNA, we obtained the consistent data (Fig. $6 \mathrm{c}$ and Supplementary Fig. 7a). The possibility that
GCG affected the transfection efficiency was ruled out (Supplementary Fig. 7b).

To test the cytotoxicity of GCG, different dosages of GCG were used to treat cells, cell viability were measured $48 \mathrm{~h}$ after the treatment. Our data showed that the doses of GCG used in our study did not cause an obvious cell death, and the 50\% cytotoxicity concentration $\left(\mathrm{CC}_{50}\right)$ was calculated (Supplementary Fig. 7c). We then examined the LLPS of $\mathrm{N}$ protein with the application of increasing concentrations of GCG, the results showed that $12.5 \mu \mathrm{M}$ was sufficient to block the $\mathrm{N}$ protein LLPS (Supplementary Fig. 7d, e). We further titrated the concentrations of GCG below $10 \mu \mathrm{M}$ and found that $6-8 \mu \mathrm{M}$ were the starting concentrations for GCG to inhibit LLPS of N protein (Fig. 6d, e). By using EMSA, we showed that the presence of GCG significantly impaired the RNA-binding of $\mathrm{N}$ protein (Fig. 6f). In addition, by incubating $\mathrm{N}$ with GCG, we showed the direct binding of GCG and N protein (Fig. 6g). We further used GCGbeads to pull-down proteins in cells expressing $\mathrm{N}$, and found that GCG selectively bound to N (Fig. 6h). Previously, our group reported that epigallocatechin gallate (EGCG), a structural isomer of GCG inhibited interferon production by disrupting the interaction between GTPase-activating protein-( $\mathrm{SH} 3$ domain)binding protein 1 (G3BP1) and Cyclic GMP-AMP synthase (cGAS) ${ }^{47}$. We then tested the effect of EGCG on blocking the RNA-triggered LLPS of N protein. Interestingly, although these two molecules are isomers, EGCG had much weaker effect on the inhibition of N-RNA condensation (Supplementary Fig. 7f, g). Taken together, GCG directly bound $\mathrm{N}$ protein and disrupted N LLPS.

GCG suppresses SARS-CoV-2 replication. We next examined whether GCG could inhibit N protein LLPS in the context of SARS-CoV-2 infection. To do so, we obtained the antibody against SARS-CoV-2 $\mathrm{N}$ protein, and the specificity of the antibody was verified (Supplementary Fig. 7h, i). We then observed the N LLPS upon SARS-CoV-2 infection, robust formation of $\mathrm{N}$ condensates was observed in infected cells (Fig. 7a-c). These data indicated that $\mathrm{N}$ protein indeed underwent LLPS during the SARS-CoV-2 infection. By applying GCG treatment on SARSCoV-2 infected cells, we found that the viral titers were dramatically inhibited (Fig. $7 \mathrm{~d}$ ), and the $50 \%$ inhibitory concentration $\left(\mathrm{IC}_{50}\right)$ was calculated (Fig. 7e). The selective index (ratio of $\mathrm{CC}_{50}$ to $\mathrm{IC}_{50}$ ) was 3.5. Importantly, the administration of GCG significantly impaired the LLPS of N protein during SARS-CoV-2 infection (Fig. 7f, g). To rule out the possibility that GCG restrict SARS-CoV-2 at the entry step, cells were infected with SARSCoV-2 for $1 \mathrm{~h}$ and then treated with GCG for $24 \mathrm{~h}$. The viral titers were measured, and the results showed that GCG still significantly inhibited the viral replication (Fig. 7h). Together, our data suggested that GCG effectively inhibited SARS-CoV-2 replication and most likely through the disruption of LLPS of N.

\section{Discussion}

SARS-CoV-2 is still raging around the world. The daily confirmed cases are about 491,000 and this number is still increasing. The development of strategies to combat SARS-CoV-2 holds the highest priority. Tremendous efforts have been made to understand the infection of SARS-CoV-2, and the spike-ACE2mediated viral entry was a major target for many studies $3,4,48,49$. In addition to the viral entry process, it is also critical to understand the details of other molecular events in the life cycle of SARS-CoV-2, such as viral assembly and replication. Recently studies revealed that SARS-CoV-2 carries almost the largest genome in RNA virus family and rapidly replicates in cells ${ }^{8,50}$. The efficient genomic RNA package is therefore 
a

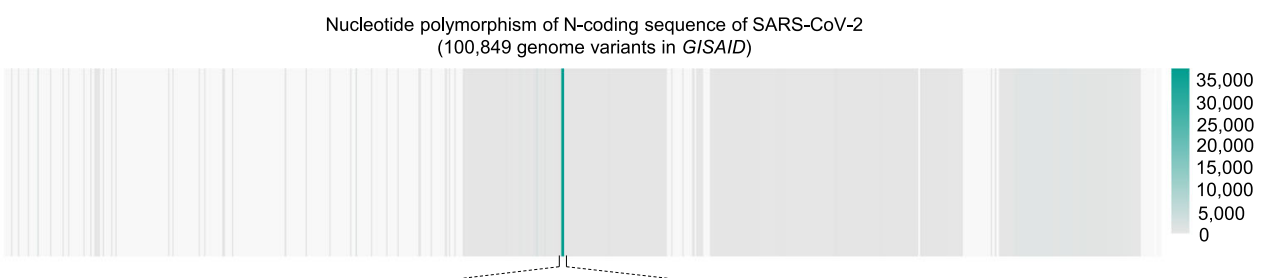

AGC AGT AGG GGA ACT TCT

R203/G204 201- Ser Ser Arg Gly Thr Ser -206

AGC AGT AAA CGA ACT TCT

R203K/G204R 201- Ser Ser Lys Arg Thr

b

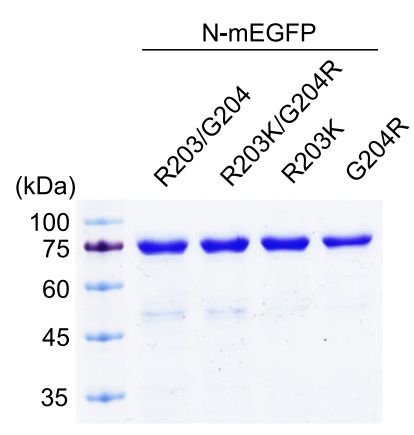

d

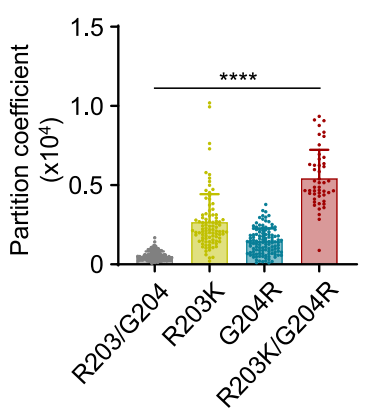

c

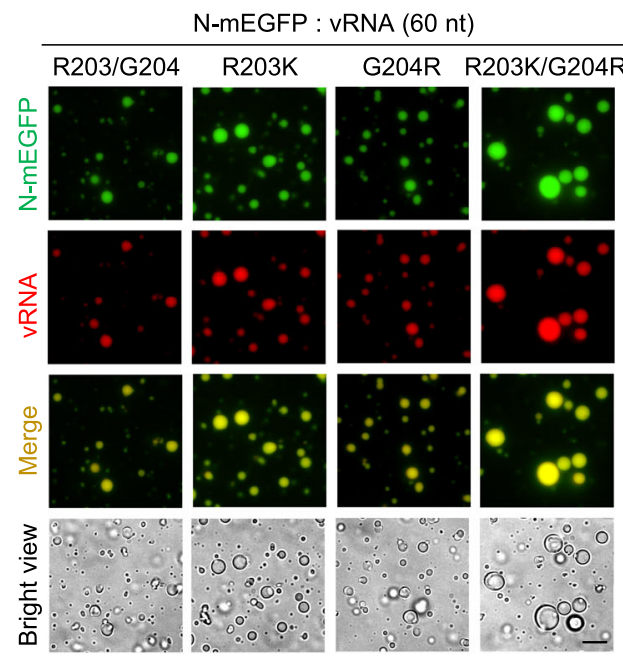

e

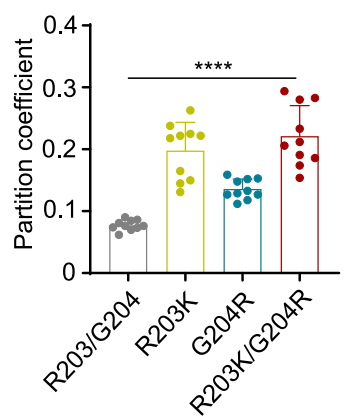

f

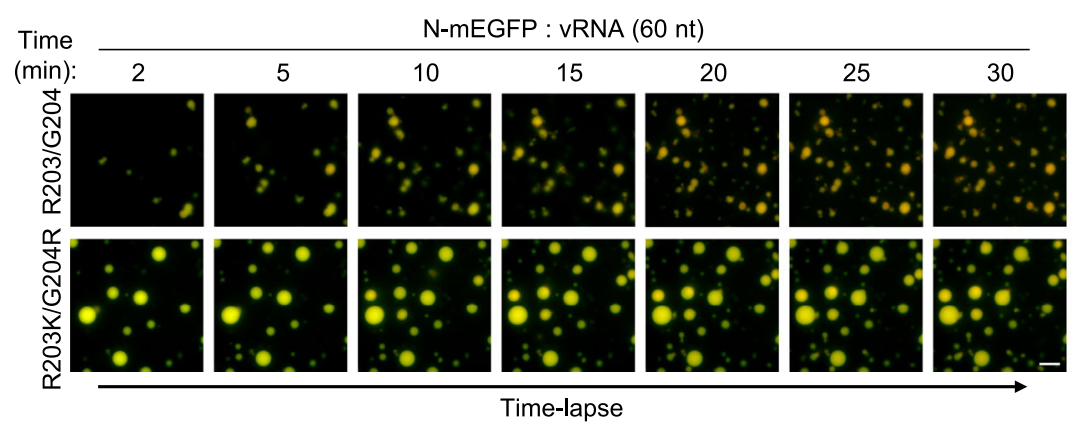

g

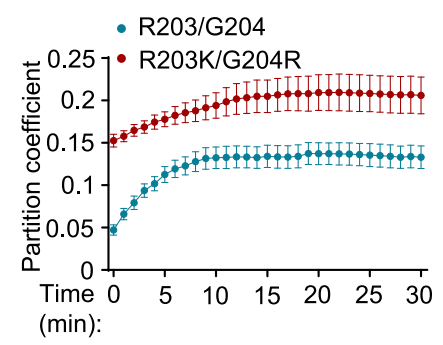

important for its replication. Investigation on the mechanisms underlying the assembly of SARS-CoV-2 will be critical in identifying new targets for treating COVID-19. Our work, by unveiling the LLPS of $\mathrm{N}$ protein with viral RNA, provided important detailed knowledges of SARS-CoV-2 assembly.
As a physicochemical process, LLPS was more and more realized to be a crucial mechanism that governing the functional organization of macromolecules in numerous biological processes $^{20,23}$. LLPS is believed to be critical in viral assembly ${ }^{29}$. A key step during the replication of coronavirus is the association 
Fig. 4 NR203K/G204R gained greater ability to undergo RNA-induced LLPS. a Distribution of N gene variants among 100,849 SARS-CoV-2 genomes obtained from GISAID database. Colors indicated the nucleotide variability numbers from 100,849 genomes. The high-frequency trio-nucleotide polymorphism variant (GGG-to-AAC) is shown. b Coomassie brilliant blue-stained SDS-PAGE gel of purified variants of N-mEGFP protein. c-e LLPS of different N-mEGFP variants, in the presence of $50 \mathrm{ng} / \mu \mathrm{l} 60$-nt vRNA (c). The partition coefficient of fluorescence intensity per droplet (d) and the partition coefficient of total fluorescence intensity in each view (e) were calculated. From left to right, $n=1232,803,897,431$ droplets (d) from 10 randomly selected views (e). f, $\mathbf{g}$ Time-lapse imaging of NR203/G204-mEGFP and NR203K/G204R-mEGFP proteins (20 $\mu$ M) in the presence of Cy5-labeled 60-nt vRNA $(40 \mathrm{ng} / \mu \mathrm{l})(\mathbf{f})$, and the partition coefficient $(n=8$ randomly selected views) of total fluorescence intensity in each view $(\mathbf{g})$. Scale bars, $10 \mu \mathrm{m}(\mathbf{c}, \mathbf{f})$. Error bars, mean with s.d. (d, e) and mean with s.e.m. $(\mathbf{g})$. Two-tailed unpaired Student's $t$-test $(\mathbf{d}, \mathbf{e}),{ }^{\star \star \star \star} p<0.0001$. Data are representative of at least three independent experiments. Source data are provided as a Source Data file.

a

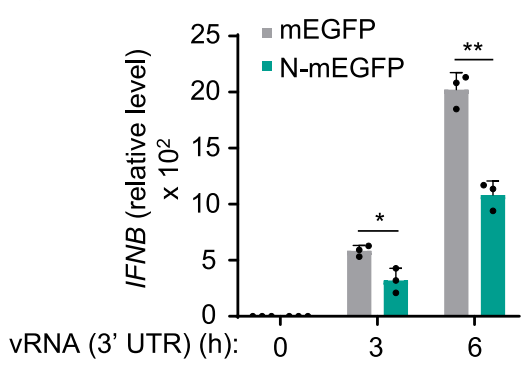

b

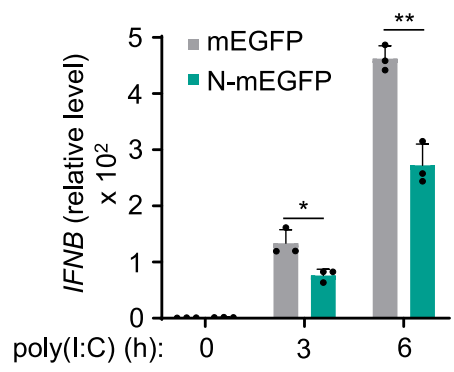

C

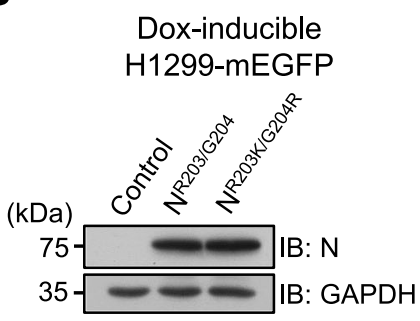

d

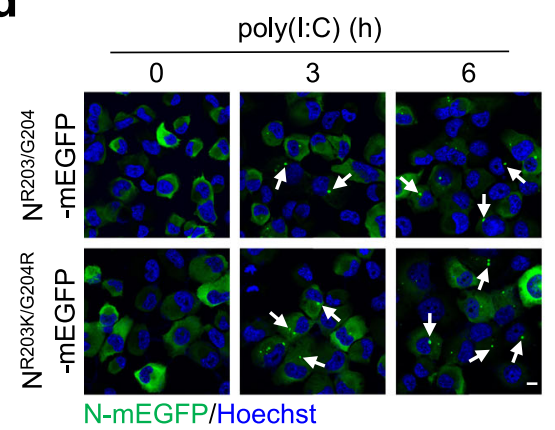

g

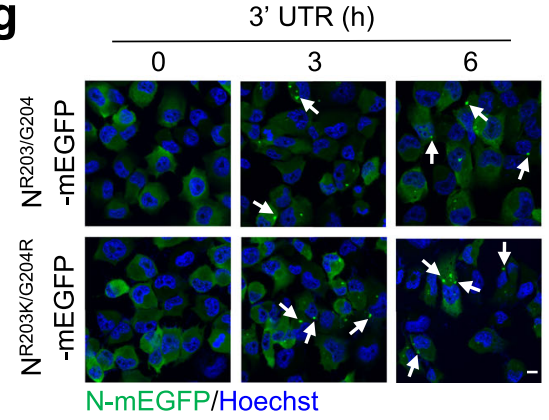

e

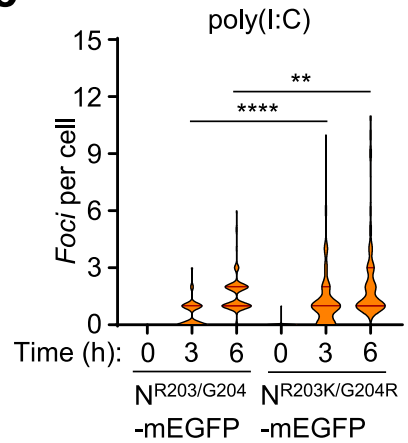

h

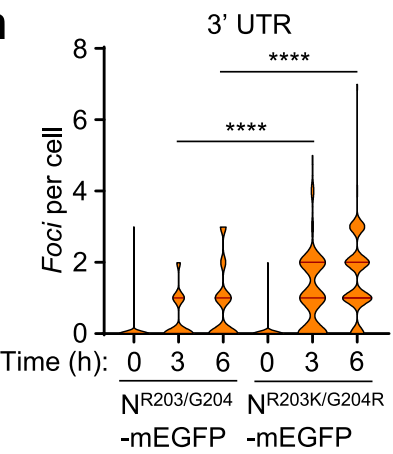

f

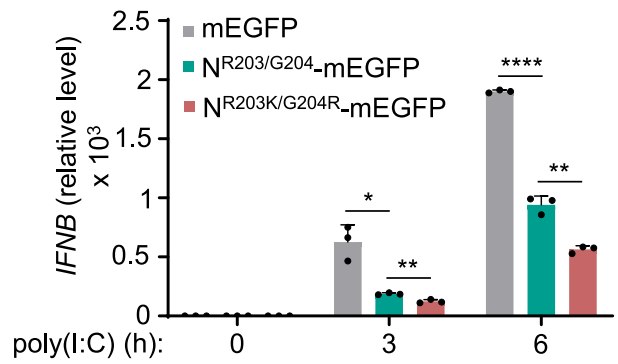

i

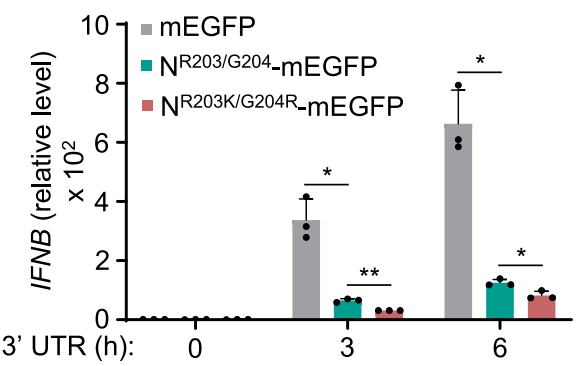

Fig. 5 N inhibits RNA-induced IFN expression. a, b qPCR analysis of IFNB expression in H1299 cells stimulated with $500 \mathrm{ng} / \mathrm{ml}$ vRNA ( $3^{\prime}$ UTR) (a) or poly $(\mathrm{I}: \mathrm{C})$ (b), following a 24-h Dox-induced expression of N-mEGFP protein ( $n=3$ biologically independent samples). c Immunoblot analysis of the Doxinduced expression of NR203/G204-mEGFP and NR203K/G204R_mEGFP proteins in H1299 cells. Control, H1299-mEGFP cells. d, e Representative fluorescent images of $\mathrm{H} 1299$ cells stimulated with $1 \mu \mathrm{g} / \mathrm{ml}$ poly(I:C) (d). Foci of NR203/G204-mEGFP and NR203K/G204R-mEGFP proteins per cell were quantified, $n=$ 100 biologically independent cells (e). f qPCR analysis of IFNB expression in $\mathrm{H} 1299$ cells stimulated with $500 \mathrm{ng} / \mathrm{ml}$ poly $(\mathrm{l}: \mathrm{C}$ ), $n=3$ biologically independent samples. $\mathbf{g}$, h Representative fluorescent images of $\mathrm{H} 1299$ cells stimulated with $3 \mu \mathrm{g} / \mathrm{ml}$ vRNA (3' UTR) (g). Foci of NR203/G204-mEGFP and

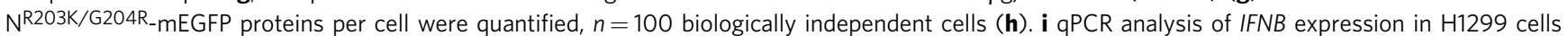
stimulated with $500 \mathrm{ng} / \mathrm{ml}$ vRNA ( $3^{\prime}$ UTR), $n=3$ biologically independent samples. Hoechst (blue), nuclear staining (d, g). Scale bars, $10 \mu \mathrm{m}$ (d, g). Violin plots showing foci of cells from each group, lines within the plots, with 25th, 50th, and 75th percentiles marked (e, h). Error bars, mean with s.d. (a, $\mathbf{b}, \mathbf{f}, \mathbf{i})$. Two-tailed unpaired Student's $t$-test $(\mathbf{a}, \mathbf{b}, \mathbf{e}, \mathbf{f}, \mathbf{h}, \mathbf{i}),{ }^{\star} P<0.05,{ }^{\star \star} P<0.01,{ }^{\star \star \star \star} P<0.0001$. Data are representative of at least three independent experiments. Source data are provided as a Source Data file. 
a
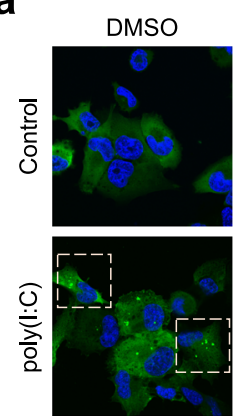

$\begin{array}{lll}. \subseteq & x \\ \text { ह } & x & x \\ N\end{array}$
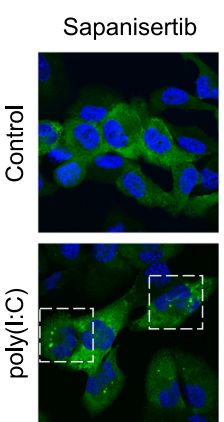

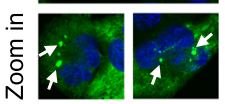

$\mathrm{N}$-mEGFP/Hoechst

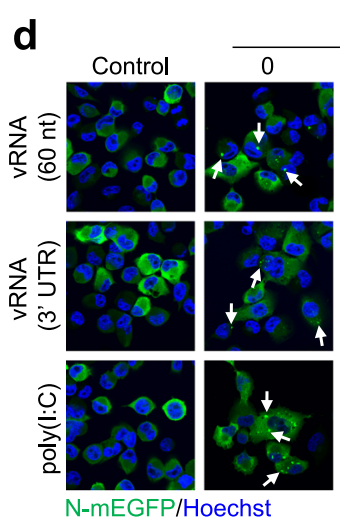

e

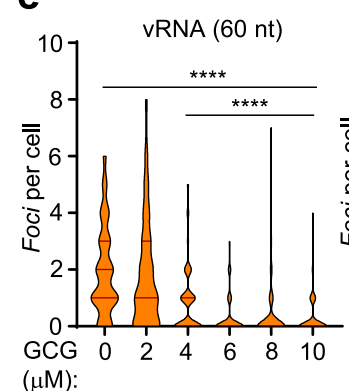

$(\mu \mathrm{M})$ :
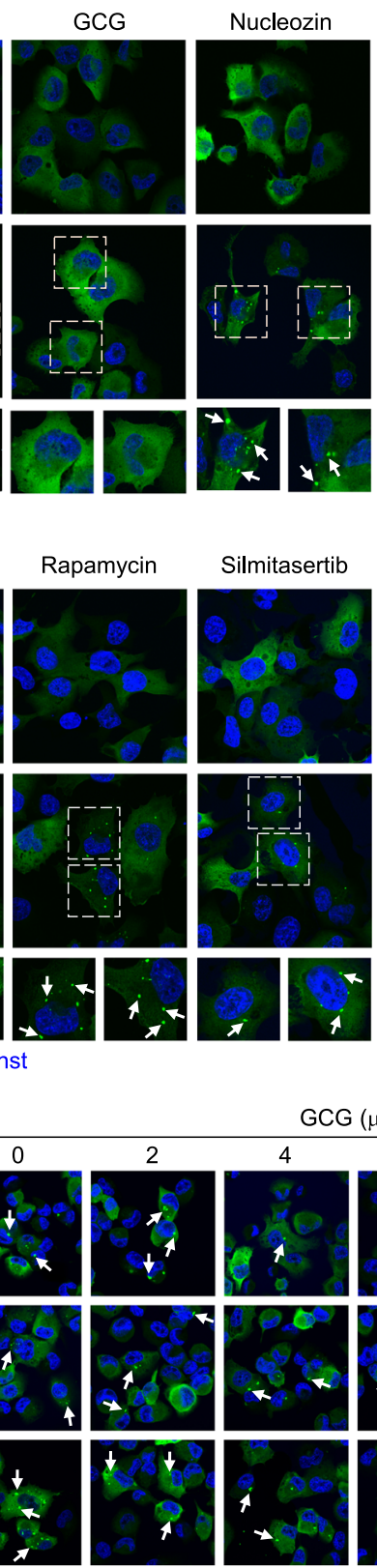

CG $(\mu \mathrm{M})$
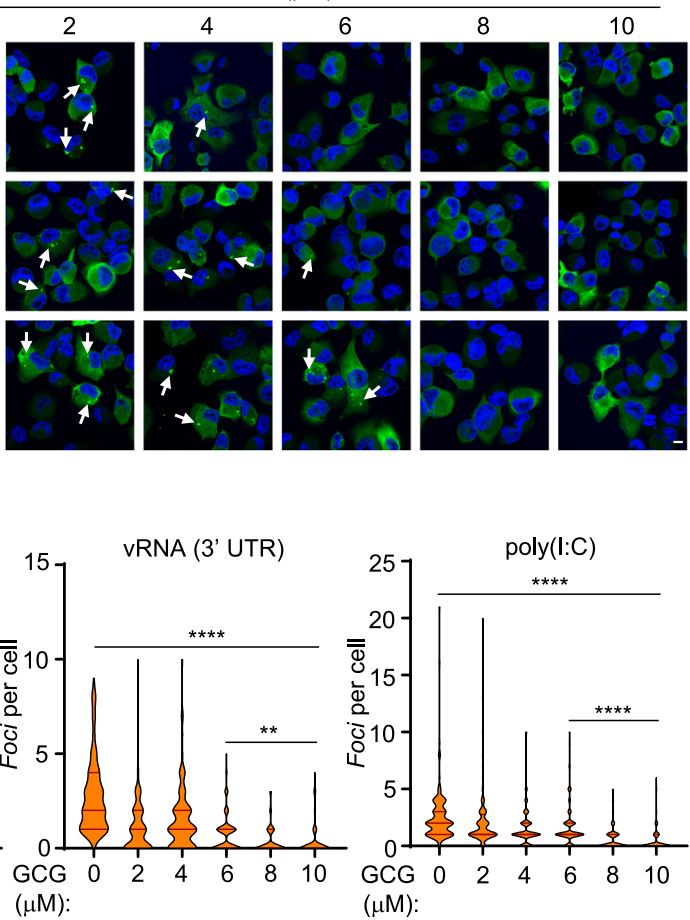

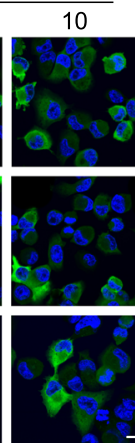

b

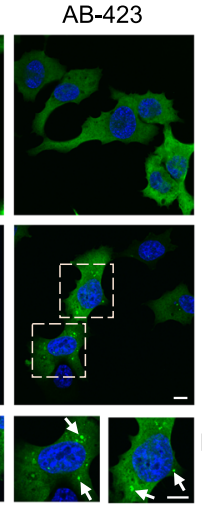

BAY41-4109

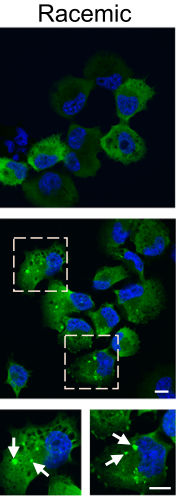

C
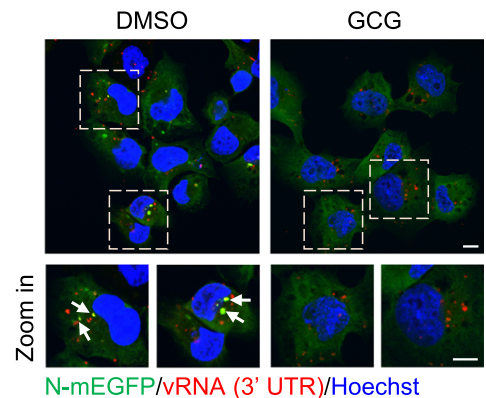

f

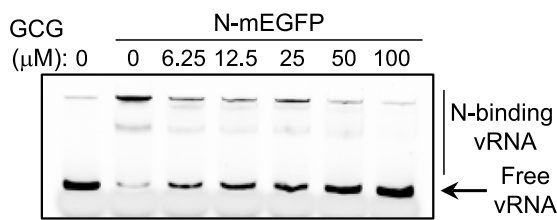

\section{g}

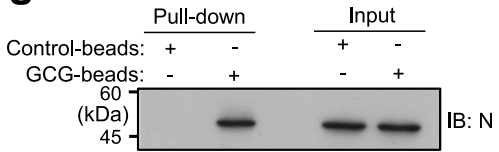

h

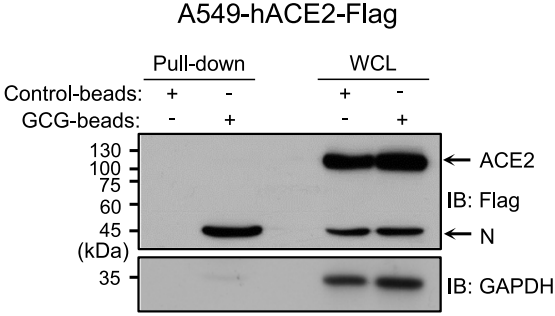

of $\mathrm{N}$ protein with viral genomic RNA and the subsequent condensation into higher-order RNA-protein complexes, which initiates the assembly of virions ${ }^{13,31}$. Our data suggested that in addition to virion assembly, the N-RNAs condensation is also important for shielding viral RNAs from host RNA sensors to avoid host immune surveillance. Interestingly, a recent proteome study identified the protein-protein interaction between $\mathrm{N}$ and G3BP1 ${ }^{9}$. G3BP1 is a core organizer of SGs assembly ${ }^{16-18}$ and SGs play a crucial role in antiviral responses against RNA viruses ${ }^{51}$. Because G3BP1 mediates the formation of SGs through 
Fig. 6 GCG inhibits LLPS of $\mathbf{N}$ protein. a, b H1299 cells with Dox-induced expression of N-mEGFP were transfected with poly(l:C) for 4 h, following a 1-h pretreatment of indicated chemicals. Representative fluorescent images are shown (a). Foci of N-mEGFP protein per cell were quantified, $n=100$ biologically independent cells (b). $10 \mu \mathrm{M} \mathrm{GCG}, 5 \mu \mathrm{M}$ Nucleozin, $200 \mu \mathrm{M}$ Naproxen, $100 \mu \mathrm{M}$ AB-423, $180 \mu \mathrm{M}$ Sapanisertib, $50 \mu \mathrm{M}$ Rapamycin, $37 \mu \mathrm{M}$ Silmitasertib, $100 \mu \mathrm{M}$ TMCB and $10 \mu \mathrm{M}$ BAY41-4109 Racemic were used. c Representative fluorescent images showed the effect of GCG on LLPS of NmEGFP protein in $\mathrm{H} 1299$ cells stimulated with $1 \mu \mathrm{g} / \mathrm{ml}$ Cy5-labeled vRNA (3' UTR). d, e H1299 cells with Dox-induced expression of N-mEGFP were transfected with $1 \mu \mathrm{g} / \mathrm{ml}$ VRNA (60 nt), vRNA (3' UTR), and poly(I:C), following the pretreatment of indicated concentrations of GCG. Representative fluorescent images were shown (d). Foci of N-mEGFP protein per cell were quantified, $n=100$ biologically independent cells (e). $\mathbf{f}$ EMSA showed the effect of GCG on RNA-binding capacity of N-mEGFP protein. Cy3-labeled vRNA (55 nt) was used as RNA probe. $\mathbf{g}$ Immunoblot analysis of GCG-N interaction in vitro. GCG pull-down assay was performed by GCG-conjugated agarose beads incubated with recombinant N protein. $\mathbf{h}$ Immunoblot analysis of GCG-N interaction in vivo. GCG pull-down assay was performed by GCG-conjugated agarose beads incubated with lysate of A549-hACE2-Flag cells transfected with pcDNA3.0-Flag-N. Hoechst (blue), nuclear staining (a, c, d). Violin plots showing foci of cells from each group, lines within the plots, with 25th, 50th, and 75th percentiles marked (b, e). Scale bars, $10 \mu \mathrm{m}(\mathbf{a}, \mathbf{c}, \mathbf{d})$. Two-tailed unpaired Student's $t$-test $(\mathbf{b}, \mathbf{e}),{ }^{\star \star} P<0.01,{ }^{\star \star \star \star} P<0.0001$. Data are representative of at least three independent experiments. Source data are provided as a Source Data file.

LLPS $^{16-18}$, $\mathrm{N}$ protein may be also involved in SARS-CoV-2 infection-induced formation of SGs through the binding to G3BP1. This involvement could be important for the host to block the translation of SARS-CoV-2 RNAs. On the other hand, $\mathrm{N}$ could also hijack G3BP1 or SGs to facilitate virion replication ${ }^{51,52}$.

By analyzing the reported genome sequences, we found that the $\mathrm{N}^{\mathrm{R} 203 \mathrm{~K} / \mathrm{G} 204 \mathrm{R}}$ variant, contained by $\sim 37 \%$ of the total sequenced SARS-CoV-2 viruses, gained greater ability to undergo RNA-triggered LLPS. Interestingly, $\mathrm{N}^{\mathrm{R} 203 \mathrm{~K} / \mathrm{G} 204 \mathrm{R}}$ exhibited a higher propensity to undergo LLPS in the presence of RNAs and showed a greater effect on the inhibition of IFN expression. This finding linked the LLPS ability of N protein with its effect on IFN inhibition. Although our results showed that $\mathrm{N}^{\mathrm{R} 203 \mathrm{~K} / \mathrm{G} 204 \mathrm{R}}$ has little effect on the death ratio of COVID-19 patients, future studies with patient clinical outcomes and the coupled SARS-CoV-2 genome sequences will provide important evidences regarding the effect of $\mathrm{N}^{\mathrm{R} 203 \mathrm{~K} / \mathrm{G} 204 \mathrm{R}}$ polymorphism on the biology of SARSCoV-2. In our study, we have also determined that the acidic microenvironment ( $\mathrm{pH}$ 6.5) is favorable condition for the RNAtriggered LLPS of N. Although this observation needs to be further investigated, this may propose another perspective for the development of antiviral strategies.

During the revision of this manuscript, a few publications also reported the LLPS of $\mathrm{N}^{53-57}$. Our work, however, not only revealed the RNA-triggered LLPS of $\mathrm{N}$ as an important molecular event during the life cycle of SARS-CoV-2, but also found that GCG can inhibit SARS-CoV-2 replication by disrupting the LLPS of N. Our findings thus present GCG as a lead compound for the design of anti-SARS-CoV-2 drugs. Given that $\mathrm{N}$ protein is a highly conserved protein factor shared by the coronavirus family ${ }^{58}$, targeting $\mathrm{N}$ protein represents a novel avenue for drug discovery, not only for SARS-CoV-2, but also for the potential new coronavirus in the future.

\footnotetext{
Methods

Antibodies and reagents. Anti-Flag M2 (F3165, 1:5000) was from Sigma-Aldrich; anti-N (40143-R019, 1:5000) was from Sino-Biological; anti-N (ARG66782, 1:1000) was from Arigo Biolaboratories; anti- $\beta$-Actin (20536-1-AP, 1:2000) was from Proteintech Group. Anti-human GAPDH (1:5000) was prepared in our laboratory and generated by immunizing rabbits with human GAPDH protein. Naproxen ${ }^{42}$ (T0855), Nucleozin ${ }^{43}$ (T7330), (-)-Gallocatechin gallate ${ }^{44}$ (T3807), Sapanisertib ${ }^{9}$ (T1838), Rapamycin ${ }^{9}$ (T1537), and Silmitasertib ${ }^{9}$ (T2259) were from TargetMol. AB- $423^{45}$ (HY-112142) was from MedChemExpress. BAY41-4109 Racemic ${ }^{46}$ (S0285) was from Selleck. TMCB ${ }^{9}$ (B7464) was from APExBIO. (-)-Epigallocatechin gallate ${ }^{47}$ (E4143) and Doxycycline hyclate (D9891) were from SigmaAldrich. Poly(I:C) (tlrl-pic) and 5'ppp-dsRNA (tlrl-3prna) were from InvivoGen. Full-length SARS-CoV-2 $3^{\prime}$ UTR and its complementary RNA were in vitro transcribed and labeled with HyperScribe T7 High Yield Cyanine 5 (Cy5) RNA Labeling Kit (K1062, APExBIO), and the annealed dsRNA ( $3^{\prime}$ UTR) was from the two transcribed RNAs. Cyanine 3 (Cy3)-labeled 55-nt vRNA (segment of 5' UTR), Cy5-labeled 10-nt to 60-nt vRNA (segment of Nsp1) and 6-carboxy-fluorescein (FAM)-labeled ssDNA were generated by Tsingke Biological Technology. Sequence
} information is provided in Supplementary Data 3.
Cell culture and transfection. H1299 (ATCC \#CRL-5803) cells were cultured in RPMI-1640 medium containing 10\% FBS, $2 \mathrm{mM} \mathrm{L-glutamine,} 100 \mathrm{U} \mathrm{ml}^{-1}$ penicillin, and $100 \mathrm{mg} \mathrm{ml}^{-1}$ streptomycin. A549 (ATCC \#CCL-185) and A549-hACE2Flag cells (this paper) were cultured in MCCOY'S 5A containing 10\% FBS, $1.5 \mathrm{mM}$ L-glutamine, $100 \mathrm{U} \mathrm{ml}^{-1}$ penicillin, and $100 \mathrm{mg} \mathrm{ml}^{-1}$ streptomycin. All the cell lines were tested routinely and confirmed to be free of mycoplasma contamination. Transfection of RNAs and ssDNA were performed with Lipofectamine 2000 (Invitrogen). Lenti-virus for the preparation of $\mathrm{N}$-expressing cells were produced in HEK293T (ATCC \#CRL-3216) cells.

Plasmids. cDNA encoding N protein of SARS-CoV-2 was from Sango Biotech. We subcloned the coding sequence of $\mathrm{N}$ protein into pcDNA3.0-Flag vector for transient expression, and into pET28a(+) vector linked with C-terminal mEGFP for recombinant protein purification. mEGFP, N-mEGFP, and N $\mathrm{N}^{\mathrm{R} 203 \mathrm{~K} / \mathrm{G} 204 \mathrm{R}_{-}}$ mEGFP were subcloned into pCDX-Tet-On vector with an N-terminal Flag tag and fused with an mEGFP tag at C-terminus for the inducible expression in cells. Five truncations ( $\mathrm{N}^{\mathrm{NTD}}, \mathrm{N}^{\mathrm{CTD}}, \mathrm{N}^{\triangle \mathrm{NTD}}, \mathrm{N}^{\triangle C T D}$, and $\mathrm{N}^{\mathrm{NTD}-\mathrm{CTD}}$ ) and three mutations $\left(\mathrm{N}^{\mathrm{R} 203 \mathrm{~K}}, \mathrm{~N}^{\mathrm{G} 204 \mathrm{R}}\right.$, and $\left.\mathrm{N}^{\mathrm{R} 203 \mathrm{~K} / \mathrm{G} 204 \mathrm{R}}\right)$ were generated from full-length $\mathrm{N}$ mEGFP and subcloned into pET28a(+) vector.

Cell viability assay. A549-hACE2-Flag cells were seeded into 96-well plates at a density of 10,000 cells per well and incubated with GCG at the indicated concentrations for $48 \mathrm{~h}$. The cell viability was analyzed with CellTiter One Solution Cell Proliferation Assay (MTS) (G3580, Promega) according to the manufacturer's instruction. $50 \%$ cytotoxicity concentration $\left(\mathrm{CC}_{50}\right)$ was calculated by non-linear regression analysis.

N gene variant identification. Complete SARS-CoV-2 genome sequences $(100,849)$ updated on September 18th, 2020 were downloaded from GISAID database (https://www.gisaid.org). To extract all $\mathrm{N}$ gene sequences, "Exonerate 2.2.0" software ${ }^{59}$ was used to align $\mathrm{N}$ protein-coding sequences to the SARS-CoV-2 genome sequences (-model protein2 genome: bestfit -score $5-g y$ ). The gene sequences of $\mathrm{N}$ protein were aligned with MUSCLE $3.8 .31^{60}$ and the annotations and visualizations of mutation sites were processed within R 3.6.0 (https://cran.rproject.org).

The correlation analysis between mutation frequencies and death ratio. The frequencies of R203K/G204R polymorphism of N protein were calculated with each country and the death ratio information of indicated countries were obtained from WHO website (https://covid19.who.int/). The correlation between the mortality and R203K/G204R polymorphism of $\mathrm{N}$ protein was calculated with a linear regression model within R 3.6.0. The subgroup analysis was performed stratified by different continents.

Sequence alignment analysis. The sequence alignment of SARS-CoV-2 $\mathrm{N}$ protein and SARS-CoV N protein (GenBank: AY278741.1) was analyzed and visualized through the msa package within R 3.6.061.

Phase separation prediction analysis of SARS-CoV-2 proteins. IDR scores of all SARS-CoV-2 proteins were calculated with an IUPred $2 A$ python script $3.7 .3^{32}$ for each amino acid. A score greater than 0.5 was regarded as intrinsically disordered and the percentage of amino acids with scores greater than 0.5 for each protein was calculated. Modular domains were predicted with InterProScan 5.31-70.062 and we used the predicted results of pfam and SMART for further analysis. Prion-like domains were identified with $P L A C C^{36}$, foci-formation propensity was calculated with catGranule ${ }^{34}, \mathrm{Pi}-\mathrm{Pi}$ interactions were analyzed with P-Score ${ }^{35}$, and LLPS ability was predicted with an extra machine learning prediction tool PSPredictor ${ }^{33}$ The charges of $\mathrm{N}$ protein were analyzed according to DDX4-like predictor ${ }^{39}$ and 
a

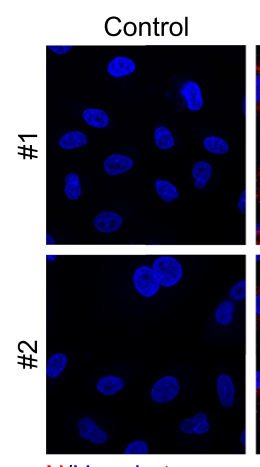

N/Hoechst b

SARS-CoV-2
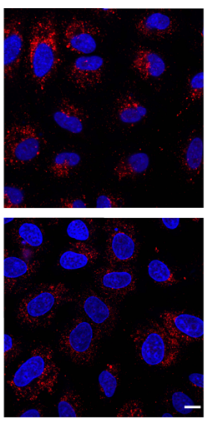

d

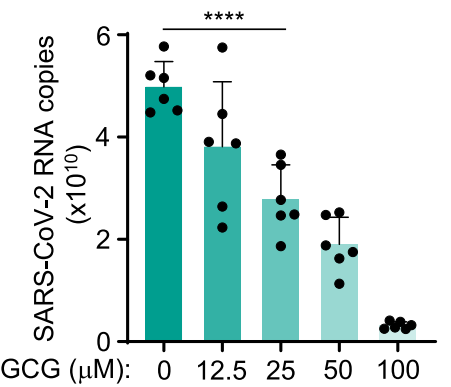

C

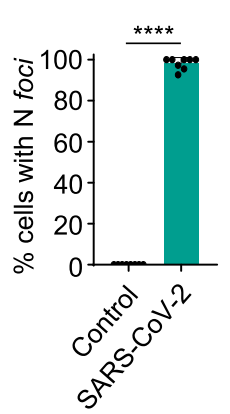

e

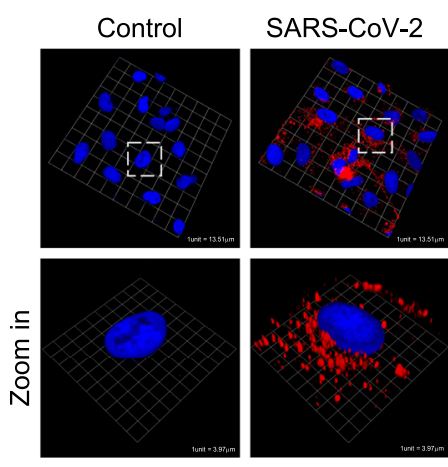

N/Hoechst

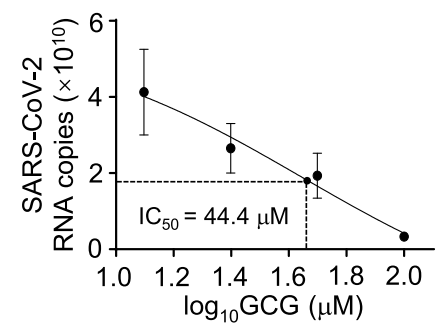

f

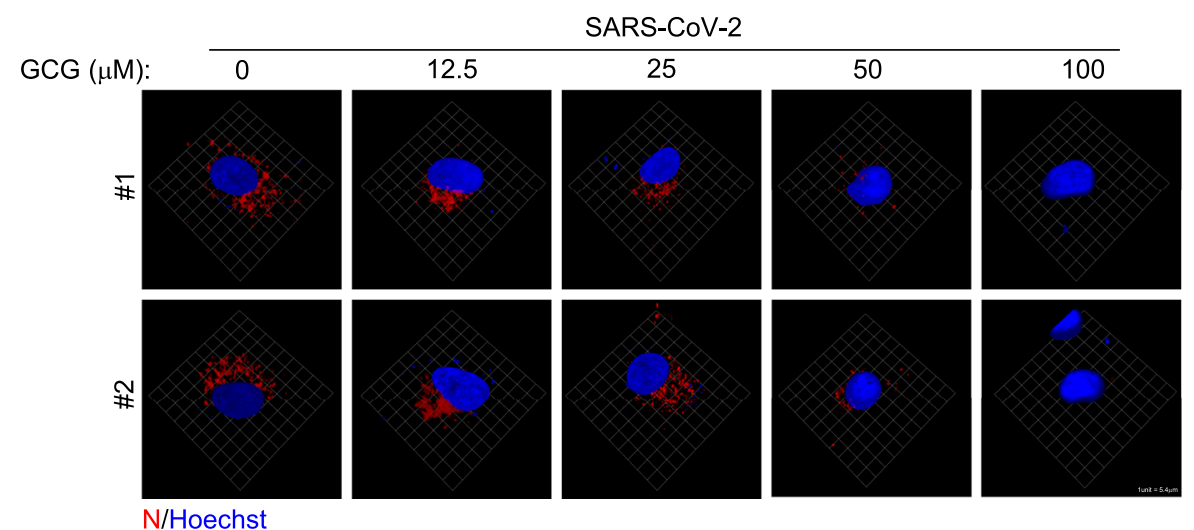

g

SARS-CoV-2

h
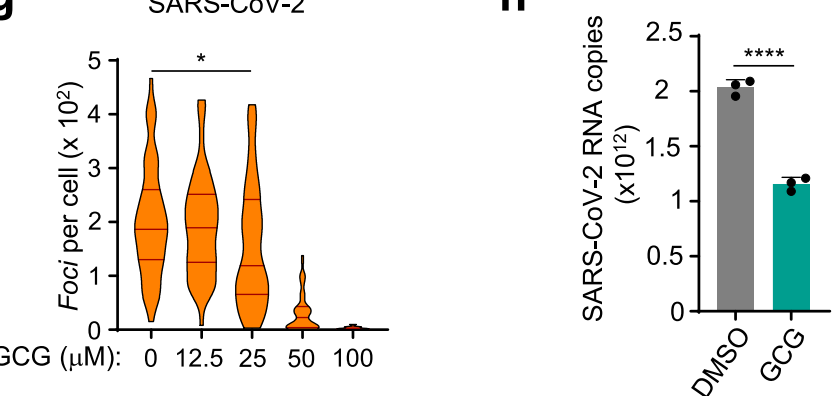

Fig. 7 GCG suppresses SARS-CoV-2 replication. a, b Immunofluorescence analysis of N protein in A549-hACE2-Flag cells infected with SARS-CoV-2 for $24 \mathrm{~h}$ (a). The percentage of cells with N protein foci was quantified, $n=8$ biologically independent samples, 20 randomly selected views were analyzed in each sample (b). Scale bar, $10 \mu \mathrm{m}$. c 3D images were obtained by Zeiss LSM 880 confocal microscope and reconstituted by Volocity 6.1.1. d, e The inhibitory effect of GCG on the replication of SARS-CoV-2, $n=6$ biologically independent samples (d). IC 50 was calculated, $n=5$ biologically independent samples (e). The infection was performed after 1-h pretreatment of GCG. $\mathbf{f}, \mathbf{g}$ Representative immunofluorescent images showed the inhibitory effect of GCG on SARS-CoV-2 N protein. 3D images were obtained by Zeiss LSM 880 confocal microscope and reconstituted by Volocity 6.1 .1 (f). Violin plots showing foci of cells ( $n=50$ biologically independent cells) from each group, lines within the plots, with 25th, 50th, and 75th percentiles marked (g). $\mathbf{h}$ Cells were infected with SARS-CoV-2 for $1 \mathrm{~h}$ followed by 24-h GCG treatment, $n=3$ biologically independent samples. Representative images were shown. SARS-CoV-2 was used at an $\mathrm{MOI}$ of 1 . Hoechst (blue), nuclear staining (a, c, f). Error bars, mean with s.d. (b, d, e, g, h). Two-tailed unpaired Student's $t$-test, ${ }^{\star} P<0.05$, ${ }^{\star \star \star \star} P<0.0001$. Data are representative of at least three independent experiments. Source data are provided as a Source Data file. 
the amino acid frequencies of $\mathrm{N}$ protein were analyzed according to $R+Y$ predictor $^{38}$ within R 3.6.0.

GCG pull-down assay. Pull-down assays were previously described ${ }^{47}$. Briefly, GCG was conjugated with cyanogen bromide ( $\mathrm{CNBr}$ )-activated agarose beads (C500099, Sangon Biotech). The recombinant N protein (40588-V08B) was from Sino-Biological. A549-hACE2-Flag cells were transfected with pcDNA3.0-Flag-N for $24 \mathrm{~h}$ and then lysed with lysis buffer $(20 \mathrm{mM}$ Tris- $\mathrm{HCl}, \mathrm{pH} 7.5 ; 0.5 \%$ Nonidet P40; $250 \mathrm{mM} \mathrm{NaCl} ; 3 \mathrm{mM}$ EDTA and $3 \mathrm{mM} \mathrm{EGTA}$ ) containing complete protease inhibitor cocktail (04693132001, Roche), followed by centrifugation at $20,000 \times g$ for $20 \mathrm{~min}$ at $4{ }^{\circ} \mathrm{C}$. The recombinant $\mathrm{N}$ protein and the supernatants from cell lysates were incubated with GCG conjugated beads at $4^{\circ} \mathrm{C}$ for $6 \mathrm{~h}$. The beads were then washed five times with lysis buffer. The proteins pulled down were examined by $10 \%$ SDS-PAGE followed by immunoblotting with indicated antibodies.

Electrophoretic mobility shift assay (EMSA). The EMSA was performed to determine RNA-binding capacity of $\mathrm{N}$ protein. Recombinant full-length and truncated N-mEGFP proteins were incubated with 55-nt Cy3-labeled vRNA. The mixtures were then applied to an $8 \%$ Native-PAGE and the electrophoresis was performed in $0.5 \times \mathrm{TBE}$ (Tris-Borate-EDTA) buffer for $1 \mathrm{~h}$ at $200 \mathrm{~V}$. The gels were analyzed by ChemiScope 6100 Touch Chemiluminescence imaging system (CLiNX) and ChemiDoc MP Imaging System (Bio-Rad).

RNA isolation and quantitative PCR (qPCR). Cells were collected and total RNAs were isolated using TRI reagent (93289, Sigma-Aldrich). Total RNAs (500 ng) were reversed-transcribed to cDNA using PrimeScript RT Master Mix (RR036A, TaKaRa). qPCR was performed with PowerUp SYBR Green Master Mix (A25778, Applied Biosystems), using StepOnePlus Real-Time PCR System (Applied Biosystems) according to the manufacturer's instructions. Data were analyzed with StepOnePlus v2.2 software. Primers used are as follows: hIFNB-Fwd: $5^{\prime}$ - AGGAC AGGATGAACTTTGAC-3'; hIFNB-Rev: 5'-TGATAGACATTAGCCAGGAG-3'; hGAPDH-Fwd: 5'- GAGTCAACGGATTTGGTCGT-3' and hGAPDH-Rev: 5'TTGATTTTGGAGGGATCTCG-3'. GAPDH was used for normalization.

In vitro phase separation assay. Recombinant $\mathrm{N}$-mEGFP proteins were diluted in phase separation buffer $\left(10 \mathrm{mM} \mathrm{Na}_{3} \mathrm{PO}_{4}, 150 \mathrm{mM} \mathrm{NaCl}, \mathrm{pH}\right.$ 6.5), and RNAs were added and mixed in glass-bottom cell culture dishes (801002, NEST) for microscopic observation and image acquirement.

Fluorescence recovery after photobleaching (FRAP). Recombinant mEGFPtagged $\mathrm{N}$ proteins were used to performed FRAP assays in vitro. Selected regions were bleached with a 488-nm laser pulse. The fluorescence intensity was collected every $1 \mathrm{~s}$ and normalized to the intensity before bleaching. For in vivo FRAP assays, H1299 cells were seeded on the glass bottom cell culture dishes and treated with $100 \mathrm{ng} \mathrm{ml}^{-1}$ Dox for the inducible expression of N-mEGFP. After 12-h Dox treatment, the cells were transfected with $1 \mu \mathrm{g} \mathrm{ml}^{-1}$ poly(I:C) for another $6 \mathrm{~h}$. FRAP assays were performed with 488 -nm laser pulse and the fluorescence intensity was collected every $0.5 \mathrm{~s}$ in vivo and normalized to the intensity before bleaching.

Protein expression and purification. Constructs for recombinant protein purification were transformed into E. coli BL21 (DE3) strain (S106-02, GenStar), and $0.6 \mathrm{mM}$ isopropyl- $\beta$-D-1-thiogalactopyranoside (IPTG) (VA20321, GenStar) was used to induce the expression of recombinant proteins. Cells were collected and resuspended in lysis buffer $\left(20 \mathrm{mM} \mathrm{Na}_{3} \mathrm{PO}_{4}, 1.5 \mathrm{M} \mathrm{NaCl}, 20 \mathrm{mM}\right.$ imidazole, $\mathrm{pH}$ 7.5). Following the sonication and centrifugation, the cleared supernatants were purified with Nickle-coupled agarose beads (G106-01, GenStar) according to the manufacturer's instructions.

Formation of $\mathbf{N}$ condensates in vivo. H1299 cells were seeded in 24-well plates and treated with $100 \mathrm{ng} \mathrm{ml}^{-1}$ Dox for $12 \mathrm{~h}$ to induce the expression of N-mEGFP. Then the cells were treated with different chemicals as indicated concentrations, followed by transfection with different RNAs. Cells were fixed with $4 \%$ paraformaldehyde for 10-15 $\mathrm{min}$ at room temperature, and the nuclei were stained with Hoechst for $10 \mathrm{~min}$. Images were acquired using Zeiss LSM 880 confocal microscope or DeltaVision Deconvolution microscope.

Virus RNA detection. A549-hACE2-Flag cells were pre-treated with GCG for $1 \mathrm{~h}$, and then infected with SARS-CoV-2 nCoV-SH01 at an MOI of 1 for $24 \mathrm{~h}$, or cells were infected with SARS-CoV-2 for $1 \mathrm{~h}$ followed by 24 -h GCG treatment. Total RNAs were extracted from cells and viral RNAs were determined using the TaqPath 1-Step RT-qPCR Master Mix (A15299, Thermo Fisher Scientific). Primers and probes used are as follows: SARS-CoV-2-N-Fwd: $5^{\prime}$-GACCCCAAAATCAG CGAAAT-3'; SARS-CoV-2-N-Rev: 5'-TCTGGTTACTGCCAGTTGAATCTG-3' and SARS-CoV-2-N-Probe: 5'-FAM-ACCCCGCATTACGTTTGGTGGACCBHQ1-3'. 50\% inhibitory concentration $\left(\mathrm{IC}_{50}\right)$ was calculated by non-linear regression analysis.
Statistical analysis. To determine the partition coefficient of indicated groups, 8 or 10 microscopy images were randomly selected, and the fluorescence intensity was acquired with Volocity 6.1.1 ${ }^{63}$. Partition coefficient of total fluorescence intensity was calculated as the total fluorescence intensity of droplets divided by the bulk fluorescence intensity of background. Partition coefficient of fluorescence intensity per droplets was calculated as average fluorescence intensity of droplets divide by the bulk fluorescence intensity per pixel of background.

GraphPad Prism 8.0 was used to perform the statistical analysis. Statistical data are presented as mean with s.d. or s.e.m. as indicated in figure legends. The fluorescence intensity was calculated by Volocity 6.1.1. A standard two-tailed unpaired Student's $t$-test was used for statistical analysis of two groups.

Reporting summary. Further information on research design is available in the Nature Research Reporting Summary linked to this article.

\section{Data availability}

Complete SARS-CoV-2 genome sequences $(100,849)$ updated on September 18th, 2020 were downloaded from GISAID database (https://www.gisaid.org). The death ratio information updated on September 18th, 2020 was obtained from WHO website (https:// covid19.who.int/). The annotations and visualizations of mutation sites, the correlation analysis between mutation frequencies and death ratio, the sequence alignment of SARS$\mathrm{CoV}-2 \mathrm{~N}$ protein and SARS-CoV N protein, and the amino acid frequencies of $\mathrm{N}$ protein were analyzed within R 3.6.0 (https://cran.r-project.org). The full-length genome sequence of SARS-CoV-2 $\mathrm{nCoV}-\mathrm{SH} 01$ strain (accession no. MT121215) and the sequence of SARS-CoV (accession no. AY278741.1) are downloaded from GenBank. Other data related to this study are available from the corresponding author upon reasonable request. Source data are provided with this paper.

\section{Code availability}

We provided the code that we programmed and used in this study on GitHub at https:// github.com/TintingLi/Nprotein_LLPS_analysis.

Received: 27 January 2021; Accepted: 9 March 2021; Published online: 09 April 2021

\section{References}

1. Zhu, N. et al. A novel coronavirus from patients with pneumonia in China, 2019. N. Engl. J. Med. 382, 727-733 (2020).

2. $\mathrm{Wu}, \mathrm{F}$. et al. A new coronavirus associated with human respiratory disease in China. Nature 579, 265-269 (2020).

3. Wang, Q. et al. Structural and functional basis of SARS-CoV-2 entry by using human ACE2. Cell 181, 894-904.e899 (2020).

4. Hoffmann, M. et al. SARS-CoV-2 cell entry depends on ACE2 and TMPRSS2 and is blocked by a clinically proven protease inhibitor. Cell 181, 271-280. e278 (2020).

5. Wang, C., Horby, P. W., Hayden, F. G. \& Gao, G. F. A novel coronavirus outbreak of global health concern. Lancet 395, 470-473 (2020).

6. Sanders, J. M., Monogue, M. L., Jodlowski, T. Z. \& Cutrell, J. B. Pharmacologic treatments for coronavirus disease 2019 (COVID-19): a review. Jama 323, 1824-1836 (2020).

7. Zhou, P. et al. A pneumonia outbreak associated with a new coronavirus of probable bat origin. Nature 579, 270-273 (2020).

8. Kim, D. et al. The architecture of SARS-CoV-2 transcriptome. Cell 181, 914-921.e910 (2020).

9. Gordon, D. E. et al. A SARS-CoV-2 protein interaction map reveals targets for drug repurposing. Nature 583, 459-468 (2020).

10. Grifoni, A. et al. A sequence homology and bioinformatic approach can predict candidate targets for immune responses to SARS-CoV-2. Cell Host Microbe 27, 671-680.e672 (2020).

11. Peng, Y. et al. Structures of the SARS-CoV-2 nucleocapsid and their perspectives for drug design. Embo J. 39, e105938 (2020).

12. Chang, C. K. et al. Modular organization of SARS coronavirus nucleocapsid protein. J. Biomed. Sci. 13, 59-72 (2006).

13. Vennema, H. et al. Nucleocapsid-independent assembly of coronavirus-like particles by co-expression of viral envelope protein genes. Embo J. 15, 2020-2028 (1996).

14. McBride, R., van Zyl, M. \& Fielding, B. C. The coronavirus nucleocapsid is a multifunctional protein. Viruses 6, 2991-3018 (2014).

15. Monette, A. et al. Pan-retroviral nucleocapsid-mediated phase separation regulates genomic RNA positioning and trafficking. Cell Rep. 31, 107520 (2020).

16. Sanders, D. W. et al. Competing Protein-RNA interaction networks control multiphase intracellular organization. Cell 181, 306-324.e328 (2020).

17. Yang, P. et al. G3BP1 is a tunable switch that triggers phase separation to assemble stress granules. Cell 181, 325-345.e328 (2020). 
18. Guillén-Boixet, J. et al. RNA-induced conformational switching and clustering of G3BP drive stress granule assembly by condensation. Cell 181, 346-361. e317 (2020).

19. Burke, K. A., Janke, A. M., Rhine, C. L. \& Fawzi, N. L. Residue-by-residue view of in vitro FUS granules that bind the C-terminal domain of RNA polymerase II. Mol. Cell 60, 231-241 (2015).

20. Boeynaems, S. et al. Protein phase separation: a new phase in cell biology. Trends Cell Biol. 28, 420-435 (2018).

21. Franzmann, T. M. \& Alberti, S. Prion-like low-complexity sequences: key regulators of protein solubility and phase behavior. J. Biol. Chem. 294, 7128-7136 (2019).

22. Riback, J. A. et al. Stress-triggered phase separation is an adaptive, evolutionarily tuned response. Cell 168, 1028-1040.e1019 (2017).

23. Brangwynne, C. P. et al. Germline P granules are liquid droplets that localize by controlled dissolution/condensation. Science 324, 1729-1732 (2009).

24. Shin, Y. \& Brangwynne, C. P. Liquid phase condensation in cell physiology and disease. Science 357, eaf4382 (2017).

25. Banani, S. F., Lee, H. O., Hyman, A. A. \& Rosen, M. K. Biomolecular condensates: organizers of cellular biochemistry. Nat. Rev. Mol. Cell Biol. 18, 285-298 (2017).

26. Hubstenberger, A. et al. P-body purification reveals the condensation of repressed mRNA regulons. Mol. Cell 68, 144-157.e145 (2017).

27. Beckham, C. J. \& Parker, R. P bodies, stress granules, and viral life cycles. Cell Host Microbe 3, 206-212 (2008).

28. Jobe, F., Simpson, J., Hawes, P., Guzman, E. \& Bailey, D. Respiratory syncytial virus sequesters NF- $\mathrm{kB}$ subunit $\mathrm{p} 65$ to cytoplasmic inclusion bodies to inhibit innate immune signaling. J. Virol. 94, e01380-20 (2020).

29. Guseva, S. et al. Measles virus nucleo- and phosphoproteins form liquid-like phase-separated compartments that promote nucleocapsid assembly. Sci. Adv. 6, eaaz7095 (2020).

30. Heinrich, B. S., Maliga, Z., Stein, D. A., Hyman, A. A. \& Whelan, S. P. J. Phase transitions drive the formation of vesicular stomatitis virus replication compartments. mBio 9, e02290-17 (2018).

31. Zúñiga, S. et al. Coronavirus nucleocapsid protein is an RNA chaperone. Virology 357, 215-227 (2007).

32. Mészáros, B., Erdos, G. \& Dosztányi, Z. IUPred2A: context-dependent prediction of protein disorder as a function of redox state and protein binding. Nucleic Acids Res. 46, W329-w337 (2018).

33. Sun, T. et al. Prediction of liquid-liquid phase separation proteins using machine learning. Preprint at https://www.biorxiv.org/content/10.1101/ 842336v1 (2019).

34. Bolognesi, B. et al. A concentration-dependent liquid phase separation can cause toxicity upon increased protein expression. Cell Rep. 16, 222-231 (2016).

35. Vernon, R. M. et al. Pi-Pi contacts are an overlooked protein feature relevant to phase separation. Elife 7, e31486 (2018).

36. Lancaster, A. K., Nutter-Upham, A., Lindquist, S. \& King, O. D. PLAAC: a web and command-line application to identify proteins with prion-like amino acid composition. Bioinformatics 30, 2501-2502 (2014)

37. Sabari, B. R. et al. Coactivator condensation at super-enhancers links phase separation and gene control. Science 361, eaar3958 (2018).

38. Wang, J. et al. A molecular grammar governing the driving forces for phase separation of prion-like RNA binding proteins. Cell 174, 688-699.e616 (2018)

39. Nott, T. J. et al. Phase transition of a disordered nuage protein generates environmentally responsive membraneless organelles. Mol. Cell 57, 936-947 (2015).

40. Li, P. et al. Phase transitions in the assembly of multivalent signalling proteins. Nature 483, 336-340 (2012)

41. Lu, X., Pan, J., Tao, J. \& Guo, D. SARS-CoV nucleocapsid protein antagonizes IFN- $\beta$ response by targeting initial step of IFN- $\beta$ induction pathway, and its C-terminal region is critical for the antagonism. Virus Genes 42, 37-45 (2011).

42. Zheng, W. et al. Naproxen exhibits broad anti-influenza virus activity in mice by impeding viral nucleoprotein nuclear export. Cell Rep. 27, 1875-1885. e1875 (2019)

43. Amorim, M. J., Kao, R. Y. \& Digard, P. Nucleozin targets cytoplasmic trafficking of viral ribonucleoprotein-Rab11 complexes in influenza A virus infection. J. Virol. 87, 4694-4703 (2013).

44. Roh, C. A facile inhibitor screening of SARS coronavirus $\mathrm{N}$ protein using nanoparticle-based RNA oligonucleotide. Int J. Nanomed. 7, 2173-2179 (2012).

45. Mani, N. et al. Preclinical profile of AB-423, an inhibitor of Hepatitis B virus pregenomic RNA encapsidation. Antimicrob. Agents Chemother. 62, e0008218 (2018).

46. Deres, K. et al. Inhibition of hepatitis B virus replication by drug-induced depletion of nucleocapsids. Science 299, 893-896 (2003).

47. Liu, Z. S. et al. G3BP1 promotes DNA binding and activation of cGAS. Nat. Immunol. 20, 18-28 (2019).
48. Hansen, J. et al. Studies in humanized mice and convalescent humans yield a SARS-CoV-2 antibody cocktail. Science 369, 1010-1014 (2020).

49. Chi, X. et al. A neutralizing human antibody binds to the $\mathrm{N}$-terminal domain of the Spike protein of SARS-CoV-2. Science 369, 650-655 (2020).

50. Bojkova, D. et al. Proteomics of SARS-CoV-2-infected host cells reveals therapy targets. Nature 583, 469-472 (2020).

51. McCormick, C. \& Khaperskyy, D. A. Translation inhibition and stress granules in the antiviral immune response. Nat. Rev. Immunol. 17, 647-660 (2017).

52. Hou, S. et al. Zika virus hijacks stress granule proteins and modulates the host stress response. J. Virol. 91, JVI.00474-17 (2017).

53. Chen, $\mathrm{H}$. et al. Liquid-liquid phase separation by SARS-CoV-2 nucleocapsid protein and RNA. Cell Res. 30, 1143-1145 (2020)

54. Perdikari, T. M. et al. SARS-CoV-2 nucleocapsid protein phase-separates with RNA and with human hnRNPs. Embo J. 39, e106478 (2020)

55. Savastano, A., de Opakua, Ibáñez, Rankovic, A., Zweckstetter, M. \& Nucleocapsid, M. protein of SARS-CoV-2 phase separates into RNA-rich polymerase-containing condensates. Nat. Commun. 11, 6041 (2020).

56. Iserman, C. et al. Genomic RNA elements drive phase separation of the SARS CoV-2 nucleocapsid. Mol. Cell 80, 1078-1091.e1076 (2020).

57. Carlson, C. R. et al. Phosphoregulation of phase separation by the SARS-CoV$2 \mathrm{~N}$ protein suggests a biophysical basis for its dual functions. Mol. Cell 80, 1092-1103.e1094 (2020)

58. Darlix, J. L., de Rocquigny, H., Mauffret, O. \& Mély, Y. Retrospective on the all-in-one retroviral nucleocapsid protein. Virus Res 193, 2-15 (2014).

59. Slater, G. S. \& Birney, E. Automated generation of heuristics for biological sequence comparison. BMC Bioinforma. 6, 31 (2005).

60. Edgar, R. C. MUSCLE: a multiple sequence alignment method with reduced time and space complexity. BMC Bioinforma. 5, 113 (2004).

61. Bodenhofer, U., Bonatesta, E., Horejš-Kainrath, C. \& Hochreiter, S. msa: an R package for multiple sequence alignment. Bioinformatics 31, 3997-3999 (2015).

62. Quevillon, E. et al. InterProScan: protein domains identifier. Nucleic Acids Res 33, W116-W120 (2005)

63. Banani, S. F. et al. Compositional Control of Phase-Separated Cellular Bodies. Cell 166, 651-663 (2016)

\section{Acknowledgements}

We thank Pei-Hui Wang (Shandong University) for providing materials. This work was supported by grants from the National Key Research and Development Program of China (No. 2020YFA0707702 to Tao. L. and No. 2020YFA0707703 to T.Z.), China National Natural Science Foundation (No. 81925017 to Tao. L.).

\section{Author contributions}

X.-M.Z., Tao.L. and T.Z. supervised the project. Tao.L., M.Z., Y.Y. and L.-M.S. designed the experiments. M.Z. and M.W. performed the phase separation and immunofluorescence assays. M.Z., J.-Q.X., X.W. and L.-M.S. purified the proteins. J.-W.C. and Y.Y. constructed the plasmids, cell lines, and performed pull-down assays. Q.-Y.H and L.-M.S. performed in vitro transcription of RNAs and performed the qPCR analysis Y.Y., W.-H.L. and H.C. performed the EMSA. L.-M.S. and X.T. tested the drug toxicity. T.-T.L. and X.-Y.Y. performed the bioinformatic analysis. R.Z., Y.-K.Z., Yin Y. and Z.-H.Y. performed the SARS-CoV-2-related experiment in the BSL-3 laboratory. M.W designed the schematic drawing of SARS-CoV-2. A.-L.L., T.Z., X.-M.Z. and Tao.L. analyzed the data. Tao.L., X.-M.Z., T.Z., W.-H.L., Z.M., Y.Y., L.-M.S. wrote and revised the manuscript.

\section{Competing interests}

The authors declare no competing interests.

\section{Additional information}

Supplementary information The online version contains supplementary material available at https://doi.org/10.1038/s41467-021-22297-8.

Correspondence and requests for materials should be addressed to T.Z., X.-M.Z. or T.L

Peer review information Nature Communications thanks Jonathon A Ditlev and other, anonymous, reviewers for their contributions to the peer review of this work. Peer review reports are available.

Reprints and permission information is available at http://www.nature.com/reprints

Publisher's note Springer Nature remains neutral with regard to jurisdictional claims in published maps and institutional affiliations. 
(c) (i) Open Access This article is licensed under a Creative Commons Attribution 4.0 International License, which permits use, sharing, adaptation, distribution and reproduction in any medium or format, as long as you give appropriate credit to the original author(s) and the source, provide a link to the Creative Commons license, and indicate if changes were made. The images or other third party material in this article are included in the article's Creative Commons license, unless indicated otherwise in a credit line to the material. If material is not included in the article's Creative Commons license and your intended use is not permitted by statutory regulation or exceeds the permitted use, you will need to obtain permission directly from the copyright holder. To view a copy of this license, visit http://creativecommons.org/ licenses/by/4.0/.

(C) The Author(s) 2021 